OPEN ACCESS

Edited by: Giovanna Suzzi, Università degli Studi di Teramo, Italy

Reviewed by: Jeffrey A. Lewis, University of Arkansas, United States Matthias Sipiczki, University of Debrecen, Hungary

*Correspondence:

Jean-Marc G. Daran

J.G.Daran@tudelft.n/ orcid.org/0000-0003-3136-8193

† orcid.org/0000-0003-2675-9712 forcid.org/0000-0002-5617-4611

Specialty section: This article was submitted to Food Microbiology, a section of the journal Frontiers in Microbiology

Received: 24 May 2018 Accepted: 02 July 2018 Published: 27 July 2018

Citation:

Diderich JA, Weening SM, van den Broek M, Pronk JT and Daran J-MG (2018) Selection of PofSaccharomyces eubayanus Variants for the Construction of

S. cerevisiae $\times S$. eubayanus Hybrids With Reduced 4-Vinyl Guaiacol

Formation. Front. Microbiol. 9:1640. doi: 10.3389/fmicb.2018.01640

\section{Selection of Pof $^{-}$Saccharomyces eubayanus Variants for the Construction of $S$. cerevisiae $x$ S. eubayanus Hybrids With Reduced 4-Vinyl Guaiacol Formation}

\author{
Jasper A. Diderich†, Susan M. Weening, Marcel van den Broek, Jack T. Pronk ${ }^{\ddagger}$ and \\ Jean-Marc G. Daran*
}

Department of Biotechnology, Delft University of Technology, Delft, Netherlands

Saccharomyces pastorianus is an interspecies hybrid between S. cerevisiae and $S$. eubayanus. The identification of the parental species of $S$. pastorianus enabled the de novo reconstruction of hybrids that could potentially combine a wide array of phenotypic traits. Lager yeasts are characterized by their inability to decarboxylate ferulic acid present in wort, a phenotype also known as Pof $^{-}$(phenolic off-flavor). However, all known S. eubayanus strains characterized so far produce clove-like aroma specific of 4-vinyl guaiacol, a decarboxylated form of ferulic acid. This study explored a nonGMO approach to construct $\mathrm{Pof}^{-} S$. eubayanus variants derived from the parental strain S. eubayanus CBS 12357. To rapidly screen a population of UV-mutagenized cells two complementary assays were developed. The first assay was based on the difference of light absorption spectra of ferulic acid and 4-vinyl guaiacol, while the second was based on the difference of sensitivity of $\mathrm{Pof}^{-}$and $\mathrm{Pof}^{+}$strains to cinnamic acid. The S. eubayanus variant HTSE042 was selected and was confirmed not to produce 4-vinyl guaiacol. Whole genome sequencing revealed that this variant lost the subtelomeric region of the CHRXIII right arm that carried the two clustered genes SePAD1- SeFDC1 whose deletion in a naïve S. eubayanus strain (CBS 12357/FM1318) resulted in an identical phenotype. Subsequently, the $\mathrm{Pof}^{-}$variant was crossed with a Pof $^{-}$S. cerevisiae partner. The resulting hybrid was not able to convert ferulic acid demonstrating the undisputable value of the mutagenized variant HTSE042 to eventually construct $S$. cerevisiae $\times S$. eubayanus hybrids with phenotypic characteristics of S. pastorianus.

Keywords: 4-vinyl guaiacol, hybridization, genetic, high-throughput screening (HTS), brewing fermentation, ferulic acid, wort sugar

\section{INTRODUCTION}

Since its discovery in Patagonia seven years ago (Libkind et al., 2011), Saccharomyces eubayanus received significant attention which to a large extent was related to its role in the reconstruction of the interspecies hybrid lager brewing yeast, S. pastorianus (Nakao et al., 2009; van den Broek et al., 2015; Okuno et al., 2016). Particularly, the S. eubayanus CBS 12357 was used in crosses aiming at the formation of artificial S. cerevisiae $\times$ S. eubayanus hybrids (Hebly et al., 2015; Krogerus et al., 2015, 2016; Mertens et al., 2015; Magalhaes et al., 2017) exhibiting novel phenotypic characteristics. 
Although S. eubayanus CBS 12357 is not able to consume all wort sugars, in particular maltotriose (Hebly et al., 2015; Krogerus et al., 2015), it exhibits several brewing traits suitable for lager brewing including growth at a temperature as low as $4^{\circ} \mathrm{C}$ (Hebly et al., 2015), proficient maltose utilization and formation of desired aroma molecules (Mertens et al., 2015). These characteristics might then be transferred to hybrids holding significant value for the brewing industry (Krogerus et al., 2017a). However, such hybrids recurrently showed formation of a clovelike, also referred to as medicinal flavor during wort fermentation (Krogerus et al., 2016, 2017b). While a clove-like aroma is highly desirable in German "hefeweizen-style" beers (Gallone et al., 2016), this characteristic is considered an off-flavor (phenolic off-flavor (Pof)) in lager beer.

The main source of the clove-like off-flavor in lager beer is the aromatic compound 4-vinyl guaiacol (4-VG). Malted barley grains that serve to prepare brewing wort are a source of a wide range of phenolic acids (e.g., p-hydroxybenzoic acid, vanillic acid, chlorogenic acid, $p$-coumaric acid, ferulic acid) (Yu et al., 2001) which possess potential health benefits (Dykes and Rooney, 2007). Among them, ferulic acid, the precursor of $4-\mathrm{VG}$ is associated with arabinoxylan essentially found in endosperm aleurone cells of cereal grains (Wilson et al., 2006). During malting and more specifically during the germination step feruloyl esterases are expressed and release feruloyl moieties from the arabinoxylan enabling subsequent hydrolysis of the polysaccharide chain by specialized enzymes (Vanbeneden et al., 2007). While a fraction of the phenolic off-flavors in beer originates directly from the wort, or through chemical conversion as a consequence of temperature and oxygen (e.g., during wort boiling or aging in the bottle) (McMurrough et al., 1996), a significant fraction results from the enzymatic conversion of ferulic acid into 4-VG by the fermenting yeast (Coghe et al., 2004). Initially only PAD1 (phenylacrylic acid decarboxylase) was associated with 4-VG formation (Clausen et al., 1994), a gene previously identified as POF1 that was implicated in phenolic off-flavour (Pof) in beer (Meaden and Taylor, 1991). A second ferulic acid decarboxylase gene (FDC1) was later characterized (Mukai et al., 2010). Both PAD1 and FDC1 form a functional gene cluster at the end of chromosome IV in Saccharomyces cerevisiae. The functional characterization of these genes revealed that both encoded enzymes are essential to express a ferulic acid decarboxylase activity (Mukai et al., 2010). However, contrasting with the initial premise, PAD1 would encode a flavin mononucleotide (FMN)-bearing protein which does not function as a decarboxylase. Rather, PAD1 would contribute to the formation of a novel cofactor necessary for the FDC1 encoded decarboxylase activity (Lin et al., 2015) similarly to UbiX function in E. coli (White et al., 2015). The phenolic acid decarboxylase encoded by FDC1 was shown to have a broad substrate range that in addition of ferulic acid also included cinnamic acid (McKenna et al., 2014), coumaric acid (Bhuiya et al., 2015) and caffeic acid (Huang et al., 2012) which suggests that PAD1-FDC1 plays a more general role in detoxification of phenolic acids (Baranowski et al., 1980; Clausen et al., 1994; Larsson et al., 2001; Richard et al., 2015). However in spite of this important function, sequence analysis of a large cohort of $S$. cerevisiae strains revealed that the Pof phenotype was highly strain dependent and has been strongly influenced by domestication. Mostly unwanted in alcoholic beverages, the absence of $4-\mathrm{VG}$ production in sake, wine, and most beer types fermenting strains was accompanied by occurrence of loss-of-function mutations in PAD1 and FDC1. In contrast wild type, baker's and bioethanol strains most systematically contained functional alleles (Gallone et al., 2016). Similarly, the wild type S. eubayanus CBS 12357 harbors functional copies of the two genes (Libkind et al., 2011; Baker et al., 2015; Hebly et al., 2015). The typical lager brewing S. pastorianus hybrids (Nakao et al., 2009; van den Broek et al., 2015) have been selected for their Pof ${ }^{-}$phenotype which was acquired during the intensive domestication history of these yeasts. As a result S. pastorianus Frohberg strains [e.g., WS34/70 (Nakao et al., 2009), CBS 1483 (van den Broek et al., 2015)] have lost the $S$. eubayanus genes caused by a translocation between the right arms of $S$. cerevisiae CHRIV and S. eubayanus CHRXIII. Simultaneously S. cerevisiae FDC1 orthologue carries a frameshift in the first half of the gene (position 521/1501) resulting in the introduction of a premature stop codon, while the S. cerevisiae PAD1 gene although full length harbors two nonsynonymous mutations resulting in replacement of His38 and Ala47 by Tyr and Val respectively (van den Broek et al., 2015). Therefore the reconstruction of artificial hybrids representative of modern industrial S. pastorianus brewing strains would require Pof $^{-}$parental strains. While multiple Pof $^{-}$S. cerevisiae strains have been characterized (Gallone et al., 2016), hitherto no Pof $^{-}$S. eubayanus strains have been described. Although yeast strain design has been enhanced by the emergence of genomeediting tools such as CRISPR-Cas9 (Jinek et al., 2012; Doudna and Charpentier, 2014), techniques that enable highly accurate genetic alterations such as gene deletion, in vivo site directed mutagenesis and novel genes chromosomal integration (DiCarlo et al., 2013; Mans et al., 2015; Jakociunas et al., 2016; de Vries et al., 2017) are available, but, consumer concerns about use of genetically modified (GM) organisms for food and beverage production preclude the use of these approaches in industry (Varzakas et al., 2007).

The objective of the present study was to construct S. eubayanus strains that lost their capacity to produce $4-\mathrm{VG}$ in order to form Pof $^{-} S$. pastorianus artificial hybrids. To select 4VG negative S. eubayanus variants from an UV-mutagenized cell suspension, a novel multi-read-out screening assay combining an assessment of growth in presence and absence of cinnamic acid and a spectrophotometric assay screening the conversion of ferulic acid was developed. Positively screened single cell lines were phenotypically and genotypically characterized and used in crosses with Pof $^{-}$S. cerevisiae strains.

\section{MATERIALS AND METHODS}

\section{Yeast Strains}

The strains used in this study are listed in Table 1. Working stock cultures were cultivated in YPD medium $\left(10 \mathrm{~g} \cdot \mathrm{L}^{-1}\right.$ Bacto yeast extract, $20 \mathrm{~g} \cdot \mathrm{L}^{-1}$ Bacto peptone and $20 \mathrm{~g} \cdot \mathrm{L}^{-1}$ glucose) until mid-exponential phase, completed with sterile glycerol [final 
TABLE 1 | Strains used in this study.

\begin{tabular}{|c|c|c|c|}
\hline Strain name & Yeast species & Genotype & Reference \\
\hline CBS 12357/FM1318 & S. eubayanus & MATa/MAT $\alpha$ SePAD1-SeFDC1/SePAD1-SeFDC1) & Libkind et al., 2011 \\
\hline IMK747 & S. eubayanus & MATa/MAT $\alpha$ Sepad1-Sefdc1 $1:: a m d S / S e P A D 1-S e F D C 1$ & This study \\
\hline IMK749 & S. eubayanus & 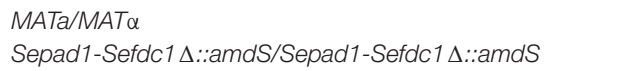 & This study \\
\hline HTSE022 & S. eubayanus & $\begin{array}{l}\text { MATa/MAT } \alpha \text { SePAD1-SeFDC1/SePAD1-SeFDC1 (UV } \\
\text { mutagenised) }\end{array}$ & This study \\
\hline HTSE023 & S. eubayanus & $\begin{array}{l}\text { MATa/MAT } \alpha \text { SePAD1-SeFDC1/SePAD1-SeFDC1 (UV } \\
\text { mutagenised) }\end{array}$ & This study \\
\hline HTSE033 & S. eubayanus & $\begin{array}{l}\text { MATa/MAT } \alpha \text { SePAD1-SeFDC1/SePAD1-SeFDC1 (UV } \\
\text { mutagenised) }\end{array}$ & This study \\
\hline HTSE037 & S. eubayanus & $\begin{array}{l}\text { MATa/MAT } \alpha \text { SePAD1-SeFDC1/SePAD1-SeFDC1 (UV } \\
\text { mutagenised) }\end{array}$ & This study \\
\hline HTSE042 & S. eubayanus & $\begin{array}{l}\text { MATa/MAT } \alpha \text { Sepad1-Sefdc1 } \Delta / \text { Sepad1-Sefdc1 } \Delta^{*}(\mathrm{UV} \\
\text { mutagenised) }\end{array}$ & This study \\
\hline IMK439 & S. cerevisiae & 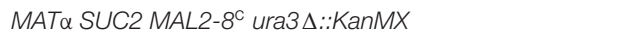 & Gonzalez-Ramos et al., 2013 \\
\hline CEN.PK113-7D & S. cerevisiae & MATa SUC2 MAL2-8C & Salazar et al., 2017 \\
\hline CEN.PK122 & S. cerevisiae & MATa/MAT $\alpha S U C 2 / S U C 2$ MAL2-8C/ MAL2-8C & Entian and Kötter, 2007 \\
\hline CBS 1483 & S. pastorianus & Prototrophic wild-type lager brewing yeast & (van den Broek et al., 2015) \\
\hline FRY153 & S. cerevisiae & $3 n$ & Hebly et al., 2015 \\
\hline IMS0408 & S. eubayanus $\times$ S. cerevisiae & 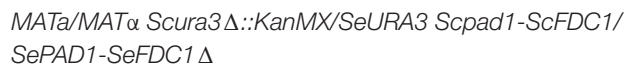 & Hebly et al., 2015 \\
\hline HTSH009 (HTSE042 × IMK439) & S. eubayanus $\times$ S. cerevisiae & $\begin{array}{l}\text { MATa/MATa Scura3 } \Delta:: K a n M X / S e U R A 3 \text { Scpad1-ScFDC1/ } \\
\text { Sepad1-Sefdc1 } \Delta^{*}\end{array}$ & This study \\
\hline HTSH010 (HTSE042 × IMK439) & S. eubayanus $\times$ S. cerevisiae & $\begin{array}{l}\text { MATa/MATa Scura3 } \Delta:: K a n M X / S e U R A 3 \text { Scpad1-ScFDC1/ } \\
\text { Sepad1-Sefdc1 } \Delta^{*}\end{array}$ & This study \\
\hline HTSH011 (HTSE042 × IMK439) & S. eubayanus $\times$ S. cerevisiae & $\begin{array}{l}\text { MATa/MATa Scura3 } \Delta:: K a n M X / S e U R A 3 \text { Scpad1-ScFDC1/ } \\
\text { Sepad1-Sefdc1 } \Delta^{*}\end{array}$ & This study \\
\hline HTSH012 (IMK749 × IMK439) & S. eubayanus $\times$ S. cerevisiae & $\begin{array}{l}\text { MATa/MATa Scura3 } \Delta:: K a n M X / S e U R A 3 \text { Scpad1-ScFDC1/ } \\
\text { Sepad1-Sefdc1 } \Delta:: a m d S\end{array}$ & This study \\
\hline HTSH013 (IMK749 × IMK439) & S. eubayanus $\times$ S. cerevisiae & 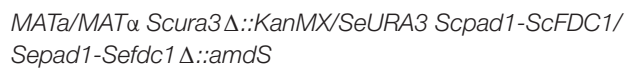 & This study \\
\hline HTSH014 (IMK749 × IMK439) & S. eubayanus $\times$ S. cerevisiae & $\begin{array}{l}\text { MATa/MATa Scura3 } \Delta:: K a n M X / S e U R A 3 \text { Scpad1-ScFDC1/ } \\
\text { Sepad1-Sefdc1 } \Delta:: a m d S\end{array}$ & This study \\
\hline
\end{tabular}

*Indicates pad1-fdc1 deletion resulting from UV mutagenesis.

concentration $20 \%(\mathrm{v} / \mathrm{v})$ ] and stored at $-80^{\circ} \mathrm{C}$ as $1 \mathrm{~mL}$ aliquots until next inoculation.

\section{Media and Growth Conditions}

Batch cultivations in shake flasks, 24-well and 96-well microtiter plates were performed in synthetic wort medium (SWM) that contained $14.4 \mathrm{~g} \cdot \mathrm{L}^{-1}$ glucose, $2.3 \mathrm{~g} \cdot \mathrm{L}^{-1}$ fructose, $85.9 \mathrm{~g} \cdot \mathrm{L}^{-1}$ maltose, $26.8 \mathrm{~g} \cdot \mathrm{L}^{-1}$ maltotriose, $5 \mathrm{~g} \cdot \mathrm{L}^{-1}\left(\mathrm{NH}_{4}\right)_{2} \mathrm{SO}_{4}, 3 \mathrm{~g} \cdot \mathrm{L}^{-1}$ $\mathrm{KH}_{2} \mathrm{PO}_{4}, 0.5 \mathrm{~g} \cdot \mathrm{L}^{-1} \mathrm{MgSO}_{4} \cdot 7 \mathrm{H}_{2} \mathrm{O}, 1 \mathrm{~mL} \cdot \mathrm{L}^{-1}$ trace element solution, $1 \mathrm{~mL} \cdot \mathrm{L}^{-1}$ vitamin solution and supplemented with the anaerobic growth factors ergosterol and Tween $80\left(0.01 \mathrm{~g} \cdot \mathrm{L}^{-1}\right.$ and $0.42 \mathrm{~g} \cdot \mathrm{L}^{-1}$ respectively), as previously described in (Verduyn et al., 1992). For screening of UV mutagenized colonies SWM was supplemented with either cinnamic acid (SWM-ca) or ferulic acid (SWM-fa) at a final concentration of $1 \mathrm{mM}$. The $0.5 \mathrm{M}$ stock solutions of ferulic acid and cinnamic acid were prepared in $100 \%$ ethanol. When the amdSYM cassette was applied as selection marker, strains were plated on synthetic medium with acetamide (SM-Ace) which contained $3 \mathrm{~g} \cdot \mathrm{L}^{-1} \mathrm{KH}_{2} \mathrm{PO}_{4}, 0.5 \mathrm{~g} \cdot \mathrm{L}^{-1} \mathrm{MgSO}_{4} \cdot 7 \mathrm{H}_{2} \mathrm{O}, 0.6 \mathrm{~g} \cdot \mathrm{L}^{-1}$ acetamide, $6.6 \mathrm{~g} \cdot \mathrm{L}^{-1} \mathrm{~K}_{2} \mathrm{SO}_{4}, 1 \mathrm{~mL} \cdot \mathrm{L}^{-1}$ of a trace element solution and $1 \mathrm{~mL} \cdot \mathrm{L}^{-1}$ of a vitamin solution (Solis-Escalante et al., 2013).

Interspecific hybrids issued from the crosses of S. eubayanus spores and S. cerevisiae MATa IMK439 (Gonzalez-Ramos et al., 2013) were selected on SMUG containing $3 \mathrm{~g} \cdot \mathrm{L}^{-1} \mathrm{KH}_{2} \mathrm{PO}_{4}$, $0.5 \mathrm{~g} \cdot \mathrm{L}^{-1} \mathrm{MgSO}_{4} \cdot 7 \mathrm{H}_{2} \mathrm{O}, 0.5 \mathrm{~g} \cdot \mathrm{L}^{-1}$ urea and $1 \mathrm{~g} \cdot \mathrm{L}^{-1}$ glutamate, $1 \mathrm{~mL} \cdot \mathrm{L}^{-1}$ of a trace element solution and $1 \mathrm{~mL} \cdot \mathrm{L}^{-1}$ of a vitamin solution (Verduyn et al., 1992) and supplemented with $200 \mu \mathrm{g} \cdot \mathrm{mL}^{-1}$ of G418 antibiotic (Wach et al., 1994).

The $\mathrm{pH}$ in all the media was adjusted to 6.0 with $\mathrm{KOH}$. Solid media were prepared by adding $2 \%(\mathrm{w} / \mathrm{v})$ agar to the media described above.

Diploid yeast strains were sporulated in sporulation liquid medium (SLM) containing $2.5 \mathrm{~g} \cdot \mathrm{L}^{-1}$ yeast extract, $15 \mathrm{~g} \cdot \mathrm{L}^{-1}$ $\mathrm{KCH}_{3} \mathrm{CO}_{2}, 20 \mathrm{~g} \cdot \mathrm{L}^{-1}$ potassium acetate and $2.5 \mathrm{~g} \cdot \mathrm{L}^{-1}$ glucose. The $\mathrm{pH}$ of SLM was adjusted to 7.0 with $\mathrm{KOH}$.

\section{Construction of Double FDC1 and PAD1 S. eubayanus Deletion Strains}

To construct a $S$. eubayanus 4-VG negative strain, the clustered genes SePAD1-SeFDC1 were deleted. For this, a deletion cassette 
including the recyclable amdSYM-cassette was constructed. The amdSYM was amplified from the plasmid pUG-amdSYM (Solis-Escalante et al., 2013) using the primers 9461 and 9462 which harbored homology to the FDC1 promoter and to the PAD1 terminator respectively (Table 2). PCR amplification was performed using Phusion Hot Start II High Fidelity Polymerase (Thermo Scientific, Waltham, MA, United States) according to the manufacturer instructions using HPLC purified, custom synthesized oligonucleotide primers (Sigma Aldrich, Zwijndrecht, Netherlands) in a Biometra TGradient Thermocycler (Biometra, Gottingen, Germany). The deletion cassette was subsequently isolated from a $1 \%(\mathrm{w} / \mathrm{v})$ agarose gel using Zymoclean Gel DNA recovery Kit (Zymo Research Corporation, Irvine, CA, United States).

Exponentially growing S. eubayanus CBS 12357 (Libkind et al., 2011) was transformed with the amplified amdSYM-cassette using the LiAc transformation protocol (Gietz and Schiestl, 2007). Cells were plated on SM-Ace plates (Solis-Escalante et al., 2013). The deletion of one of the two copies was confirmed by colony DNA isolation and PCR (Looke et al., 2011) using DreamTaq PCR Master Mix $(2 \times)$ (Thermo Fisher Scientific) with primers, 9322, 9328 and 9 (Table 2). After confirmation of the deletion a transformant was re-streaked three times on a SM-Ace plate, and a single colony isolate was stocked as IMK747.

The construction of a homozygote diploid S. eubayanus carrying the double pad1-fdc1 $\Delta::$ amdSYM mutation was performed through sporulation and tetrad dissection of IMK747. The biomass of an end-exponential culture of the strain IMK747 was collected by centrifugation $(5 \mathrm{~min} ., 3000 \times g)$ and washed twice with demineralized water. Subsequently the washed biomass was incubated in $20 \mathrm{~mL}$ SLM for $72 \mathrm{~h}$ at $20^{\circ} \mathrm{C}$ in an orbital incubator (Infors Multitron, Bottmingen, Switzerland) at $200 \mathrm{rpm}$. The presence of asci was checked by microscopic observation. The ascus walls were digested with zymolyase (Zymo research; $5 \mathrm{U} \cdot \mathrm{mL}^{-1}$ Zymolyase in $1 \mathrm{M}$ sorbitol) for $20 \mathrm{~min}$. at $20^{\circ} \mathrm{C}$. Tetrads were dissected using a MSM400 dissection microscope (Singer Instruments, Watchet, United Kingdom) and grown on SMG. After replication on SM-Ace, spores exhibiting growth were confirmed to have no PAD1-FDC1 wild type alleles left by colony PCR as described previously. After three times re-streaking, a single colony isolate was stocked and renamed IMK749. IMK749 was confirmed to be a diploid strain by its capacity to sporulate as described above.

\section{Generation of S. eubayanus Variants by Exposure to UV Light}

The diploid S. eubayanus strain CBS 12357 was grown in YPD until early stationary phase. Cells were harvested by centrifugation $\left(1000 \times g\right.$ at $4^{\circ} \mathrm{C}$ for $5 \mathrm{~min}$.) and washed with demineralised water. Then, cells were incubated for $72 \mathrm{~h}$ at $20^{\circ} \mathrm{C}$ in SLM. Presence of asci spores was checked by light microscopy. Cell density was determined with a flow cytometer (BD Accuri C6, BD Biosciences, Sparks, MD, United States). Spores were diluted in demineralised water to a final concentration of 200,000 spores $\mathrm{mL}^{-1}$. Spores were plated on SWM-agar plates (approximately 20,000 spores per plate) and subjected to UV irradiation (UVC-lamp, 36W, MSC-Advantage Biological Safety Cabinet, Thermo Fisher Scientific) for $80 \mathrm{~s}$ yielding a survival rate of circa 1\% (Hashimoto et al., 2005) and incubated for 5 days at room temperature in the dark. A set of ca. 2000 mutagenized colonies were colony-picked using a Tecan Freedom Evo 200 (Tecan, Männedorf, Switzerland) equipped with a Pickolo colony picker (Sci Robotics, Kfar Saba, Israel) and arrayed in 96-well microtiter plates filled with $200 \mu \mathrm{L}$ SWM.

\section{Screening of Strains for Reduced Ability to Produce 4-VG}

Arrayed UV mutagenized isolates were grown in 96-well microtiter plates filled with SWM at $20{ }^{\circ} \mathrm{C}$ for $48 \mathrm{~h}$ in an orbital incubator (Infors Multitron) at $250 \mathrm{rpm}$. Subsequently, the microtiter plates were replica-plated in three different media by transferring $10 \mu \mathrm{l}$ of each culture into fresh microtiter plates filled with either $200 \mu \mathrm{L}$ SWM or SWM-fa or SWMca. The reference strain S. eubayanus CBS 12357 was added to column 6 of each microtiter plate as a positive control. Column 5 of each 96-well microtiter plate only contained SWM as control for contamination in between wells. The 96-well microtiter plates were enclosed by sandwich covers and a clamp

TABLE 2 | Primers used in the study.

\begin{tabular}{|c|c|}
\hline Primer & Sequence $\left(5^{\prime}\right.$ to $\left.3^{\prime}\right)$ \\
\hline 9461 & CTTGTAGCCATACGTCTTCCAATITCGTTAACTIATCAACTAATTCCTTCGAATACCCCAGCTGAAGCTTCGTACGC \\
\hline 9462 & ТTCTATTACCTAGAAGAGCTAGTTCAGCTTATTGAAAACCCCAGGACTCTCTGCAAGATGCATAGGCCACTAGTGGATCTG \\
\hline 9 & CGCACGTCAAGACTGTCAAG \\
\hline 9322 & GCGGCTGAACATATCTCCTG \\
\hline 9328 & CGGCGAAATGCATGGATACG \\
\hline 9350 & CAATATTCGACACACCTATGCTG \\
\hline 9351 & TAGAATTGTTGACACATGGAATTCC \\
\hline Scer F2 & GCGCTITACATTCAGATCCCGAG \\
\hline Scer R2 & TAAGTTGGTTGTCAGCAAGATTG \\
\hline Seub F3 & GTCCCTGTACCAATTTAATATTGCGC \\
\hline Seub R2 & ПTTCACATCTCTTAGTCTITCCAGACG \\
\hline
\end{tabular}


system (Duetz et al., 2000). The arrayed UV-mutagenized strains were grown for 3 days at $20^{\circ} \mathrm{C}$ in an orbital incubator (Infors Multitron) at $250 \mathrm{rpm}$. Growth was determined by measuring the optical density at $660 \mathrm{~nm}$ with a Tecan Infinite M200Pro spectrophotometer. The Cinnamic Acid Sensitivity Index (CASI) was calculated as the ratio of the $\mathrm{OD}_{660 \mathrm{~nm}}$ of the culture grown in presence of cinnamic acid over the culture without cinnamic acid, after $72 \mathrm{~h}$. Maximum inhibition was set at 100, as follows:

$$
C A S I=100-\left(\frac{O D_{660} \mathrm{~nm} \text { culture with } 1 \mathrm{mM} \text { cinnamic acid }}{O D_{660} \mathrm{~nm} \text { culture without cinnamic acid }} \times 100\right)
$$

Additionally, SWM-fa culture supernatants were collected by centrifugation for $5 \mathrm{~min}$ at $2500 \times g$ at $4^{\circ} \mathrm{C}$. After transfer into a fresh plate, five-fold diluted supernatant absorption spectra between 250 and $400 \mathrm{~nm}$ were recorded using a Tecan Freedom Evo 200. For strain comparison the Ferulic Acid Conversion Index (FACI) was calculated as the ratio of the absorbance at $310 \mathrm{~nm}$ of the culture grown in the presence of $1 \mathrm{mM}$ ferulic acid after $72 \mathrm{~h}$, over the absorbance of the culture medium with $1 \mathrm{mM}$ ferulic acid at $310 \mathrm{~nm}$. Complete absence of the peak at $310 \mathrm{~nm}$ (high ferulic acid conversion) was set at 100, as follows:

$F A C I=100-\left(\frac{A b s_{310 \mathrm{~nm}} \text { culture with } 1 \mathrm{mM} \text { ferulic acid }}{A b s_{310 \mathrm{~nm}} \text { culture medium with } 1 \mathrm{mM} \text { ferulic acid }} \times 100\right)$

\section{Screening of Strains by Principal Component Analysis}

Principal component analysis was performed using RStudio, version $1.1 .383^{1}$ (RStudio, Inc., Boston, MA, United States) and $\mathrm{R}$ software, version $3.4 .3^{2}$. The softwares Ggbiplot, version $0.55^{3}$ and ggplot version 2.2.1 (Wickham, 2009) were used to visualize the principal component space.

Principal Component Analysis (PCA) was performed on a dataset comprising growth on SWM and growth in the presence of cinnamic acid after $72 \mathrm{~h}$ (as determined by $\mathrm{OD}_{660 \mathrm{~nm}}$ ) and the FACI values at 280, 290, 300, 310, 320, 330, 340, 350, and $360 \mathrm{~nm}$ of culture supernatants grown in SWM-fa.

\section{Characterization of Strains With Reduced Ability to Produce 4-VG}

Selected strains were cultivated under micro-aerobic conditions in Duetz-MTPs (Enzyscreen, The Netherlands), consisting of 24-square polypropylene deep-well plates, low-evaporation sandwich covers and extra high cover clamps (Duetz et al., 2000) at $20^{\circ} \mathrm{C}$ at $250 \mathrm{rpm}$ in an orbital incubator (Infors Multitron) in $3 \mathrm{~mL}$ SWM, SWM-ca and SWM-fa.

\section{Generation of $S$. cerevisiae $x$ S. eubayanus Hybrids}

Mass mating of S. cerevisiae IMK439 (Gonzalez-Ramos et al., 2013) and S. eubayanus IMK749 spores was done as previously described in (Hebly et al., 2015). In short, $100 \mu \mathrm{L}$ of the

\footnotetext{
${ }^{1}$ https://www.rstudio.com/

${ }^{2}$ https://www.r-project.org/

${ }^{3}$ http://github.com/vqv/ggbiplot
}

S. cerevisiae MATa IMK439 taken at mid-exponential phase was mixed with $S$. eubayanus IMK749 spores and incubated for $4 \mathrm{~h}$ at $30^{\circ} \mathrm{C}$ in an orbital incubator (Infors Multitron) at $200 \mathrm{rpm}$ before plating on SMUG selective plates. Single colony isolates were allowed to stabilize on SWM for approximately 50 generations before phenotyping and stocking. Three single potential hybrids were selected and restreaked three times on SMUG selective plates. These interspecific hybrid strains were stored and named HTSH012, HTSH013 and HTSH014. Similarly haploid vegetative S. cerevisiae IMK439 and spores of S. eubayanus HTSE042 (an UV-mutagenized variant of S. eubayanus CBS 12357 exhibiting reduced 4 -VG production) were mass-mated and plated on SMUG. The resulting hybrids were named HTSH009, HTSH010 and HTSH011. Successful hybridisation was confirmed by PCR using a primer pair specific for S. cerevisiae (Scer F2/Scer R2, Table 2) and for S. eubayanus (Seub F3/Seub R2) as described in Pengelly and Wheals (2013). Further confirmation of the hybridization was performed by flow cytometry and wholegenome sequencing.

\section{Analytical Methods}

Ferulic acid, 4-vinyl guaiacol (4-VG) and cinnamic acid were measured using an Agilent 1260 LC equipped with an 1260 Infinity Diode Array Detector measuring at $214 \mathrm{~nm}$, and an Agilent Zorbax SB-C18 Column (4.6 × 5.0, 3.5 micron) operated at $30^{\circ} \mathrm{C}$ (Koopman et al., 2012; Vos et al., 2015). A gradient of acetonitrile and $20 \mathrm{mM} \mathrm{KH} \mathrm{PO}_{4}(\mathrm{pH} 2)$ with $1 \%(\mathrm{v} / \mathrm{v})$ acetonitrile was used as eluent at a flow rate of $0.8 \mathrm{~mL} \cdot \mathrm{min}^{-1}$, increasing from $0-10 \%$ acetonitrile in $6 \mathrm{~min}$. followed by an increase to $40 \%$ acetonitrile until $23 \mathrm{~min}$. From 23 to $27 \mathrm{~min}$, $100 \% 20 \mathrm{mM} \mathrm{KH}_{2} \mathrm{PO}_{4}(\mathrm{pH} 2)$ with $1 \%$ acetonitrile was used as eluent. Ferulic acid, 4-VG and cinnamic acid standards for calibration were obtained from Sigma Aldrich. Stock solutions were prepared in $100 \%$ ethanol. Dilutions were made in milliQ water.

Staining of cells with SYTOX Green Nucleic Acid Stain was performed as described by (Haase and Reed, 2002). Stained cells were analyzed on a flow cytometer equipped with a $488 \mathrm{~nm}$ laser (BD Accuri C6, BD Biosciences). The hybrids were compared with strains of known ploidy (n/2n, S. cerevisiae CEN.PK1137D; 2n/4n, S. cerevisiae CEN.PK122; 3n/6n, S. cerevisiae FRY153) (van den Broek et al., 2015).

\section{Sequence Analysis of Strains}

Genomic DNA was prepared as described previously in (Kuijpers et al., 2016). Libraries with an average insert size of 413 bp and 323 bp for S. eubayanus CBS 12357 and S. eubayanus HTSE042, respectively, were constructed and paired-end sequenced with a read length of 150-bp as described previously (van den Broek et al., 2015).

A total of 21,345,630 and 20,998,964 reads were generated for the strains S. eubayanus CBS 12357 and HTSE042, respectively, accounting for more than $3 \mathrm{~Gb}$ of data per strain representing a minimum of 125-fold coverage of the diploid genome of S. eubayanus. Sequence reads of each strain were mapped onto S. eubayanus CBS 12357 [genome PRJNA243390, (Baker et al., 2015)] using the Burrows-Wheeler Alignment tool (BWA) and 
further processed using SAMtools (Li et al., 2009; Li and Durbin, 2010).

Single-nucleotide variations and indels were determined using Pilon (Walker et al., 2014) based on the BWA.bam output file. The Pilon results file.vcf was visualized using the Integrative Genomics Viewer IGV ${ }^{4}$. Sequence data are available at $\mathrm{NCBI}^{5}$ under Bioproject PRJNA472853.

\section{RESULTS}

\section{Deletion of SeFDC1 and SePAD1 Is Sufficient to Abolish 4-VG Production in S. eubayanus CBS 12357}

To assess the full dynamic range of 4 -VG production in S. eubayanus CBS 12357, a homozygote diploid carrying a double SePAD1-SeFDC1 deletion was constructed. A deletion cassette comprising the amdSYM marker cassette (Solis-Escalante et al., 2013) flanked by 60 bp homologous sequence to the SeFDC1 promoter and the SePAD1 terminator was amplified and transformed in S. eubayanus CBS 12357 (Figure 1A). Typically targeted deletion occurs through double cross-over mediated by homologous recombination and directed by the flanking homologous sequences. After transformation, acetamide growing transformants were genotyped by PCR for both the presence of the deletion cassette at the SePAD1-SeFDC1 locus and for the presence of the wild type locus. All transformants were heterozygote harboring both versions of the locus [deleted (485 bp) and wild type (1027 bp)] (Figure 1B). One transformant was renamed IMK747 (Figure 1B). IMK747 was sporulated and tetrads were micro-manipulated. All four spores were growing on SMG medium but replica-plating on acetamide led to a two:two segregation of the amdSYM marker (Figure 1C) confirming the heterozygote PAD1-FDC1 locus in IMK747 (MATa/MATaSepad1-Sefdc1 $\triangle:: a \operatorname{amdSYM/SePAD1-SeFDC1).~As~}$ most wild type strains, S. eubayanus CBS 12357 is homothallic, in other words after spore germination haploids have the capability to switch mating type and mate with itself to form a stable diploid stage. Therefore spore S1 (Figures 1B,C) was grown on YPD plates and subsequently streaked out to separate single colony isolates. They were sequentially grown on SMG plates and replica plated on SM-Ace medium. Acetamide growing isolates were confirmed by PCR to only carry the deleted version of the SePAD1-SeFDC1 locus. Subsequently, the PCR confirmed isolates were shown to be diploid by flow cytometry. A strain fulfilling all these characteristics (homozygote deleted SePAD1-SeFDC1 locus; diploid genome) was selected and renamed IMK749 (MATa/MATa Sepad1Sefdc1 $\Delta::$ amdSYM/Sepad1-Sefdc1 $\Delta::$ amdSYM).

The ability to convert ferulic acid into 4-VG was tested in the single heterozygote SePAD1-SeFDC1 knockout IMK747 and the double FDC1-PAD1 knockout IMK749 and compared to the parental strain S. eubayanus CBS 12357 (Figure 2). Cultures were grown in 24-deepwell plates in synthetic wort medium containing

${ }^{4} \mathrm{http} / / /$ software.broadinstitute.org/software/igv/

${ }^{5}$ https://www.ncbi.nlm.nih.gov/
$1 \mathrm{mM}$ ferulic acid (SWM-fa). The CBS 12357 strain consumed about $3 / 4$ of the supplied ferulic acid (Figure 2A). The single knockout strain IMK747 showed a ferulic acid consumption that was approximately half of CBS 12357 , while in the double PAD1FDC1 knockout IMK749 the ferulic acid concentration dropped by only 13\% (Figure 2A). In strains CBS 12357 and IMK747 the consumed ferulic acid was nearly all stoichiometrically converted into 4-VG (Figure 2B). The strain IMK749 was not exhibiting any sign of $4-\mathrm{VG}$ conversion and this in spite of a slight drop in extracellular concentration of ferulic acid.

\section{S. eubayanus IMK749 Exhibited an Exacerbated Sensitivity to Cinnamic Acid}

Naturally occurring hydroxycinnamates like ferulic acid and cinnamic acid have been shown to inhibit growth of S. cerevisiae (Baranowski et al., 1980; Clausen et al., 1994; Larsson et al., 2001). Indeed the protonated form of weak organic acids (e.g., ferulic and cinnamic acid) can freely diffuse across the membrane. Entering the cell the acid dissociates liberating a proton and therefore affecting intracellular $\mathrm{pH}$. The protons pumped out to counter the lowering $\mathrm{pH}$ are expelled at the expense of ATP creating an energy expenditure futile cycle (Mollapour et al., 2004; Hazelwood et al., 2006; Piper, 2011). In contrast, the import of 4-VG or styrene (decarboxylated product of cinnamic acid) should not result in accelerated acidification of cytosol and would not require extra ATP investment. Therefore cells having lost the ability to decarboxylate hydroxycinamates should exhibit a stronger growth inhibition. To test this characteristic, the S. eubayanus CBS 12357, IMK747 (Sepad1-Sefdc1 $\triangle$ ::amdSYM/SePAD1-SeFDC1) and IMK749 (Sepad1-Sefdc1 $\Delta::$ amdSYM/Sepad1-Sefdc1 $\Delta:: a m d S Y M) \quad$ were grown in synthetic wort medium containing $1 \mathrm{mM}$ cinnamic acid (SWM-ca). On SWM all strains showed comparable growth. Conversely, in SWM-ca, growth of the double PAD1-FDC1 knockout IMK749 was almost completely abolished, while the single knockout showed a significant reduced growth compared to the parental strain CBS 12357 (Student $t$-test $p$-value $<0.01$ ) (Figure 2C) confirming the role of PAD1-FDC1 in the conversion and detoxification of growth inhibiting cinnamic acid into styrene.

To adapt the assay to high-throughput testing, the effect of the cinnamic acid was evaluated based on biomass yield. The Cinnamic Acid Sensitivity Index (CASI) was calculated as the ratio of the optical density $\left(\mathrm{OD}_{660 \mathrm{~nm}}\right)$ of the culture grown in presence of $1 \mathrm{mM}$ of cinnamic acid over OD of the culture without cinnamic acid at the end of growth. The parental strain showed a low CASI of 0.1, while the heterozygote single Sepad1Sefdc1 $\Delta$ knock-out strain IMK747 showed a CASI of 23 , and the homozygote double Sepad1-Sefdc1 $\Delta$ knock-out IMK749 a CASI of 73, showing a high cinnamic acid sensitivity (Figure 2C).

\section{A Fast and Reliable UV-Vis Method for Ferulic Acid and 4-Vinyl-Guaiacol Determination}

Ferulic acid, cinnamic acid and 4 -VG can be measured by HPLC methods that entail up to $30 \mathrm{~min}$ analysis per sample (e.g., Bourne et al., 2000; Koopman et al., 2012; 


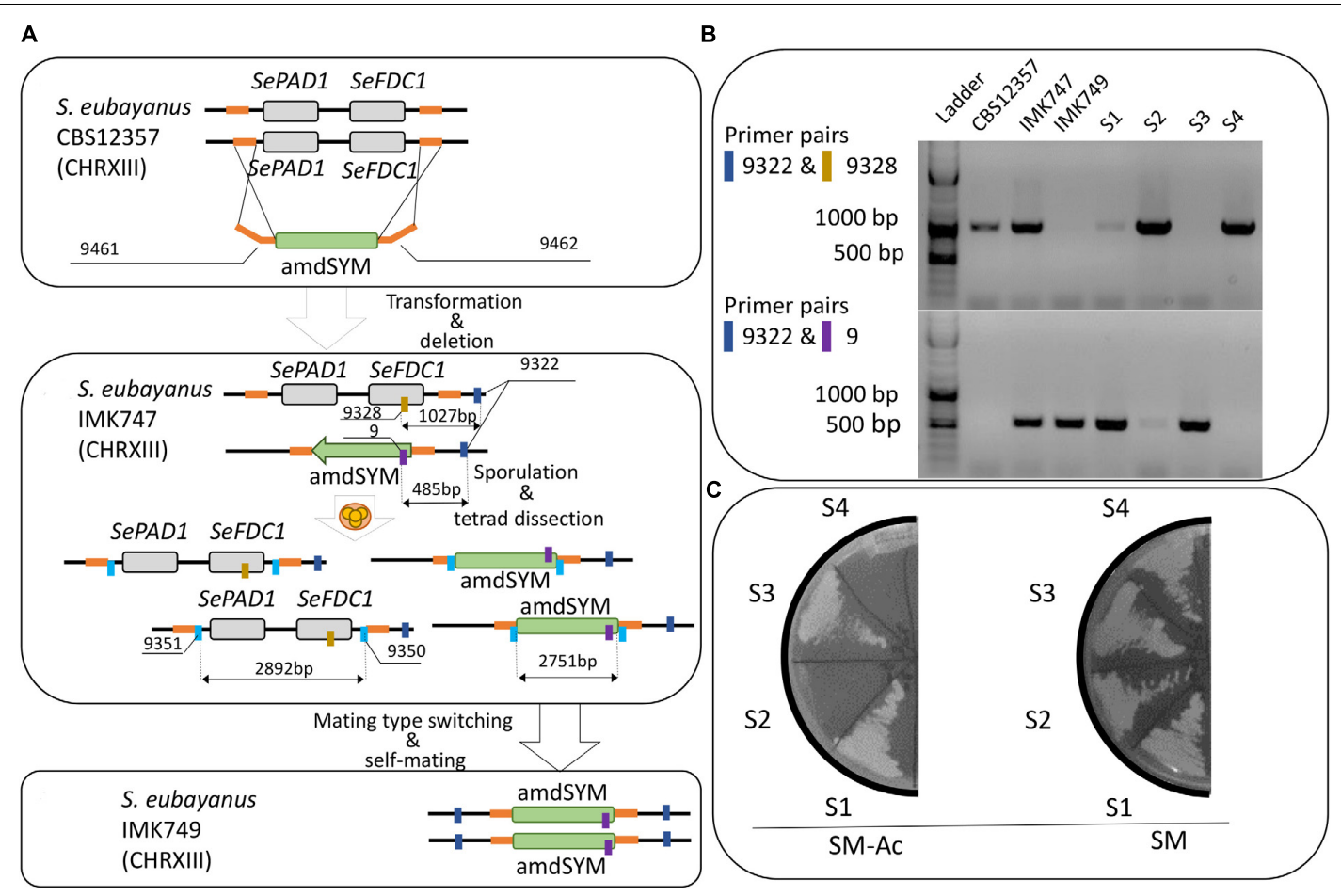

FIGURE 1 | Construction of targeted PAD1-FDC1 deletion in Saccharomyces eubayanus CBS 12357. (A-1) The deletion cassette was amplified using the primers pair 3144/3145 and the plasmid pUG-amdSYM (Solis-Escalante et al., 2013) as template. The fragment was then transformed in S. eubayanus CBS 12357. (2) Transformants were genotyped with primers pairs $9322 / 9328$ and 9322/9 to discriminate between wild type (1027 bp) and deleted (485 bp) loci respectively. Heterozygote diploid IMK747 (SePAD1-SeFDC1/Sepad1-Sefdc1 1 ::amdSYM) was sporulated. After ascus digestion the spores were dissected resulting in a two:two segregation of the PAD1-FDC1 locus. Spores were germinated. Single colony isolates of acetamide growing spores were selected and checked for ploidy. (3) A 2n isolated homozygote (Sepad1-Sefdc1 $\Delta$ ::amdSYM/Sepad1-Sefdc1 $\Delta$ ::amdSYM) was selected and renamed IMK749. (B) PCR analysis was performed to confirm correct integration of the gene disruption cassettes using amdSYM (Solis-Escalante et al., 2013) of the PAD1-FDC1 locus in S. eubayanus. PCR was carried out on reference strain CBS 12357, IMK747, IMX749 and four segregants (S1-S4) of a single tetrad of IMK747. PCRs were performed with the primers pairs 9322/9328 and 9322/9 for PAD1-FDC1 and pad1-fdc1 $\Delta$ loci, respectively. The amplification of the wild-type PAD1-FDC1 and pad1-fdc1 $\Delta$ parental strain, of the loci generated fragments of 1027 and 485 bp, respectively. (C) The four segregants (S1-S4) of a single tetrad of IMK747 were grown on SM-Ac and SM. The plates were incubated at $30^{\circ} \mathrm{C}$ and were read after 3 days.

Vos et al., 2015) a timing that is not compatible with the analysis of several thousand of samples. Therefore a new highthroughput compatible method was required. The structure difference between ferulic acid and $4-\mathrm{VG}$ is restricted to a single carboxylic group. Although saturated carboxylic groups absorb very weakly in UV-Vis, their absorptivity significantly increases when the carboxylic group is conjugated to an alkenyl function $(\mathrm{C}=\mathrm{C})$ like in the configuration of ferulic acid. UVVis absorption spectra between 200 and $400 \mathrm{~nm}$ of ferulic acid and $4-\mathrm{VG}$ revealed a clear difference at wavelengths higher than $280 \mathrm{~nm}$. The 4-VG spectrum exhibited a sharp decrease to reach $95 \%$ reduction at $300 \mathrm{~nm}$ while ferulic acid absorption remained maximal till $335 \mathrm{~nm}$ (Figure 3A). The difference in absorption characteristics enabled a highthroughput analysis of culture media in 96-well plates in a microplate spectrophotometer, which reduced sample analysis time to a couple of seconds.

The conversion capacity of ferulic acid into 4-VG in the single PAD1-FDC1 knockout IMK747 and the double PAD1FDC1 knockout IMK749 was compared to the parental strain CBS 12357. The S. eubayanus strains CBS 12357 (Pof ${ }^{+}$), IMK747 $\left(\right.$ Pof $\left.^{+}\right)$and IMK749 (Pof ${ }^{-}$) were grown in SWM-fa (Figure 3B). The absorption spectra of supernatant of 3 days old cultures were determined. The parental strain CBS 12357 spectrum showed a clear decrease in the peak at $330 \mathrm{~nm}$ compatible with the conversion of ferulic acid into 4 -VG. The single knockout strain showed a reduced diminution of the ferulic acid peak, while no decrease of the peak height at $330 \mathrm{~nm}$ was noticeable in the double knockout and the spectrum remained undistinguishable to that of the SWM control spectrum (Figure 3).

\section{Screening for UV-Mutagenized Strains With Reduced 4-VG Formation}

Although the deletion of the PAD1-FDC1 gene pair was sufficient to explain the genetic basis of a Pof $^{-}$phenotype, the reluctance to apply GM strains like IMK749 (Sepad1Sefdc1 $\Delta$ ::amdSYM/Sepad1-Sefdc1 $\Delta$ ::amdSYM) in construction of hybrids that could potentially be used in production of commercial beverages restricted the range of mutagenesis methods to approaches often referred to as "classical strain improvement" and more specifically introduction of mutations 

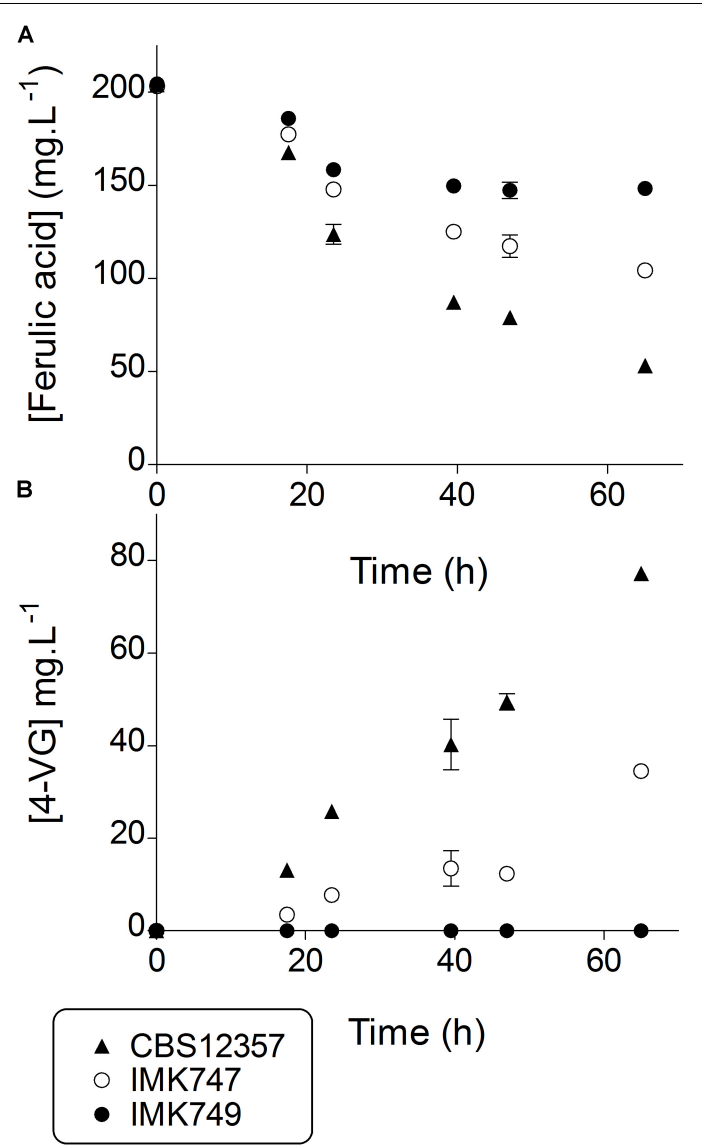

C

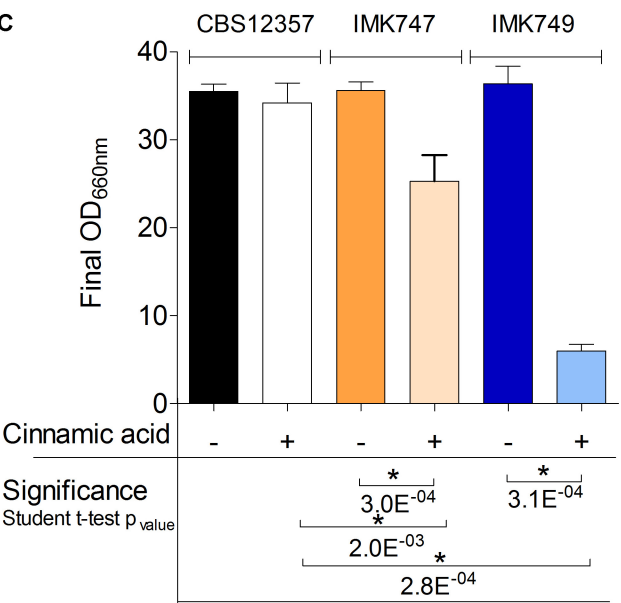

FIGURE 2 | Ferulic acid conversion and cinnamic acid sensitivity of PAD1-FDC1 deletion strains. S. eubayanus CBS 12357 (ム, SePAD1-SeFDC1 / SePAD1-SeFDC1, of $\left.^{+}\right)$, IMK747 (O, Sepad1-Sefdc1 $\Delta::$ amdSYM /

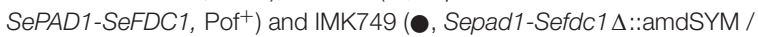
Sepad1-Sefdc1 $\Delta$ ::amdSYM, Pof $^{-}$) were grown in SWM-fa in 24-deepwell plates at $20^{\circ} \mathrm{C}$. The cultures were sampled regularly and supernatants were analyzed for ferulic (A) and 4-VG (B) concentrations. The same three strains were grown in SWM and SWM-ca in 24-deepwell plates at $20^{\circ} \mathrm{C}$. Final optical densities at $660 \mathrm{~nm}$ were compared (C). Variation in final optical density between the two conditions was evaluated by Student's $t$-test statistics (significance threshold $p=0.01$ ). The data presented show average \pm standard deviation of independent triplicate experiments. * denotes statistically significant differences.

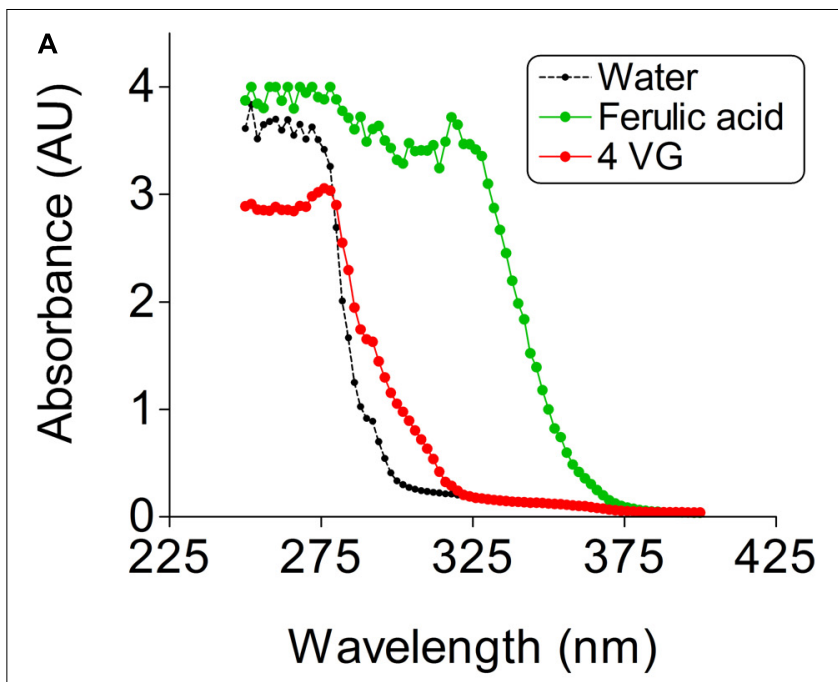

B

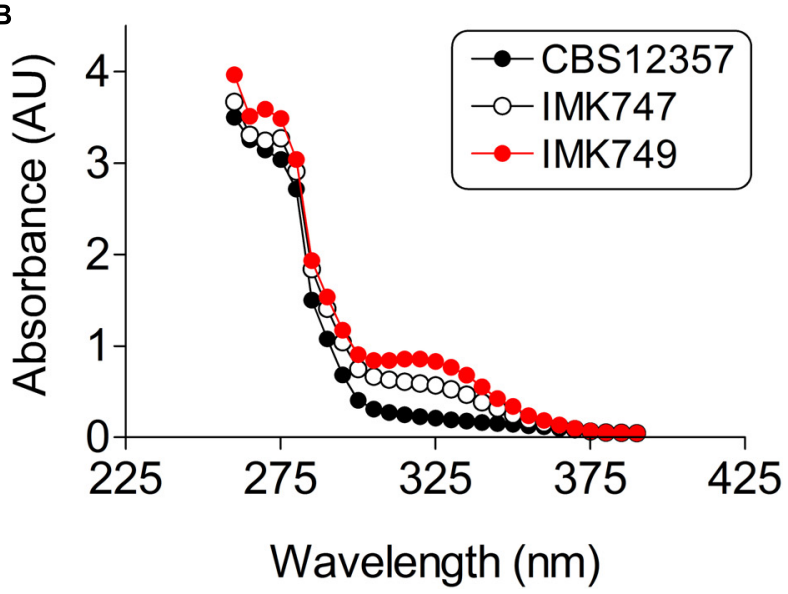

FIGURE 3 | UV-Vis absorptivity of ferulic acid, 4-vinylguaiacol (4-VG) and air. (A) Absorption spectra of wavelengths ranging from $250-400 \mathrm{~nm}$ of $1 \mathrm{mM}$ ferulic acid (0), $1 \mathrm{mM} 4-\mathrm{VG}(\mathbf{O})$ and water $(\mathbf{)})$ were determined in 96-well microtiter plates in a Tecan Infinite M200Pro spectrophotometer. The data presented show average \pm standard deviation of eight independent replicate experiments. (B) Absorption spectra of wavelengths ranging from $250 \mathrm{~nm}$ to $400 \mathrm{~nm}$ of S. eubayanus CBS 12357 (SePAD1-SeFDC1/SePAD1-SeFDC1, Pof $^{+}$) (•), IMK747 (Sepad1-Sefdc1 $\triangle$ ::amdSYM / SePAD1-SeFDC1, Pof ${ }^{+}$) (O)and IMK749 (Sepad1-Sefdc1 $\Delta$ ::amdSYM/Sepad1-Sefdc1 $\Delta$ ::amdSYM, Pof $^{-}$) (O). Cells were grown in SWM-fa at $20^{\circ} \mathrm{C}$ for $72 \mathrm{~h}$. Absorption spectra were determined of five times diluted supernatants in a Tecan Infinite M200Pro spectrophotometer.

through UV irradiation and screening of a wanted phenotype. Random mutagenesis by UV-light has been reported to cause a wide range of changes in the genome sequence of yeast cells, including transitions and transversions (Abdulovic and JinksRobertson, 2006), generating strains with a wide variety of properties.

A method to select the strains with the required properties after random mutagenesis was developed. First, general properties of the strains were assessed which comprised the determination of growth and fermentation capacity. Random 


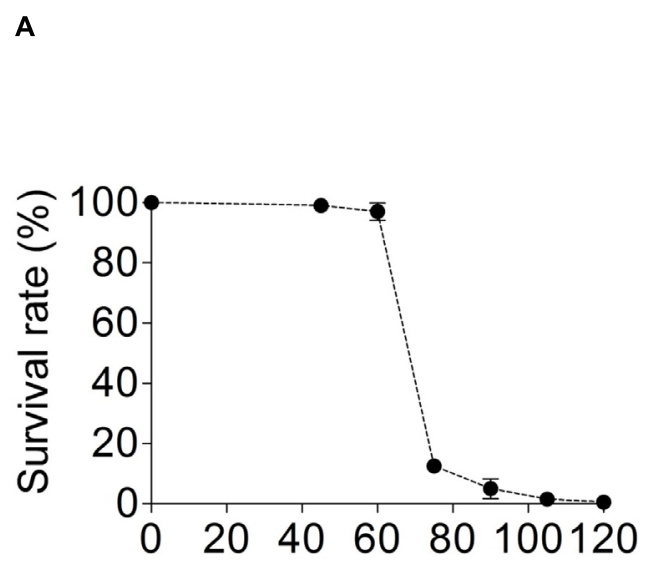

Time (s)

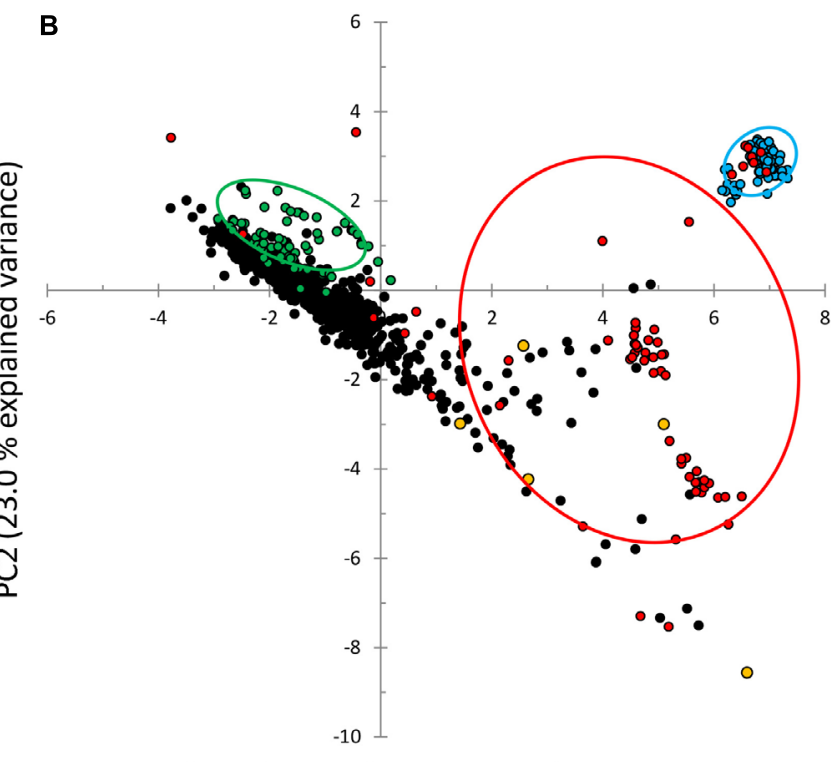

PC1 (72.7\% explained variance)

FIGURE 4 | Screening of a mutagenized population of S. eubayanus CBS 12357. (A) Survival after UV exposure of CBS 12357 spores. Plated spores were mutagenized using a UVC-lamp, 36W, MSC-Advantage Biological Safety Cabinet, Thermo Fisher Scientific. Plates were subjected to UV for different periods ranging from $45-120 \mathrm{~s}$. Surviving germinated spores were quantified after 5 days of incubation at $20^{\circ} \mathrm{C}$ in the dark. Spores sample exposed to UV for $80 \mathrm{~s}$ were further processed. (B) Principal component analysis (PCA) two-dimensional score plot of parental strains CBS 12357, UV mutagenized strains, and culture medium from cultivations in 96-well microtiter plates. About 1000 picked colonies were arrayed in 96 MTP format. The mutagenized population was further inoculated in SWM, SWM-ca and SWM-fa. Principal Component Analysis (PCA) was performed on a dataset comprising CASI readouts as determined by final $\mathrm{OD}_{660 \mathrm{~nm}}$ values after $72 \mathrm{~h}$ growth on SWM and SWM-ca, and FACI readouts as determined by discrete UV-Vis absorbance values from $280-360 \mathrm{~nm}$ with $10 \mathrm{~nm}$ intervals of SMW-fa culture supernatants after $72 \mathrm{~h}$ of cultivation. Ellipses were drawn to include $68 \%$ of the particular subgroup of cultures. The 80 replicates of the parental strain

S. eubayanus CBS 12357 were shown in green, the blank culture replicates (no cells) were shown in blue, the UV-mutagenized variants were shown in black and the UV mutagenized strains exhibiting a fitness reduction were shown in red.

mutagenesis may be a drastic method that can easily have a negative impact on the general characteristics of the yeast strain. Second, high throughput methods were applied to screen and select yeast strains which have a reduced ability (or lack the ability) to convert ferulic acid into $4-\mathrm{VG}$, as determined by the cinnamic acid sensitivity index (CASI) and the ferulic acid conversion index (FACI).
To enhance the chance of success, spores, which only contained a single copy of each chromosome, of the S. eubayanus strain CBS 12357 were UV-mutagenized for $80 \mathrm{~s}$, an exposure that resulted in a $1 \%$ survival rate that was shown to yield improved (recessive) phenotypes in industrial yeast (Hashimoto et al., 2005) (Figure 4A). Emerging colonies were arrayed in 96-well MTP format and grown on SWM. This

TABLE 3 | CASI and FACI performance indicators of the parental S. eubayanus strain CBS 12357, of single and double PAD1-FDC1 deletion mutants IMK747 and 749, and of five UV-mutagenized isolates.

\begin{tabular}{|c|c|c|c|}
\hline S. eubayanus strain & Relevant characteristics & CASI & $\mathrm{FACl}$ \\
\hline CBS 12357 & MATa/MAT $\alpha$ SePAD1-SeFDC1/SePAD1-SeFDC1) Pof ${ }^{+}$ & 0.1 & 72.7 \\
\hline IMK747 & MATa/MATa Sepad1-Sefdc1 $1:$ amdS/SePAD1-SeFDC1 Pof ${ }^{+}$ & 22.7 & 36.7 \\
\hline IMK749 & 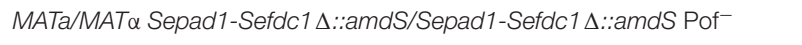 & 72.7 & 15.7 \\
\hline HTSE022 & MATa/MAT $\alpha$ SePAD1-SeFDC1/SePAD1-SeFDC1 (UV mutagenised) Pof ${ }^{+}$ & 11.8 & 59.9 \\
\hline HTSE023 & MATa/MAT $\alpha$ SePAD1-SeFDC1/SePAD1-SeFDC1 (UV mutagenised) Pof ${ }^{+}$ & 5.7 & 51.9 \\
\hline HTSE033 & MATa/MAT $\alpha$ SePAD1-SeFDC1/SePAD1-SeFDC1 (UV mutagenised) Pof ${ }^{+}$ & 12.7 & 42.9 \\
\hline HTSE037 & MATa/MATa SePAD1-SeFDC1/SePAD1-SeFDC1 (UV mutagenised) Pof ${ }^{-}$ & 60.6 & 15.7 \\
\hline HTSE042 & MATa/MATa Sepad1-Sefdc1 $\Delta /$ Sepad1-Sefdc1 $\Delta^{*}$ (UV mutagenised) Pof ${ }^{-}$ & 68.3 & 15.4 \\
\hline
\end{tabular}

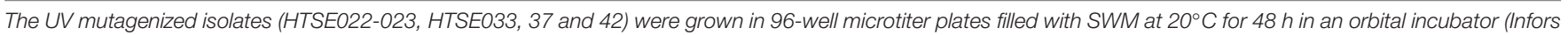

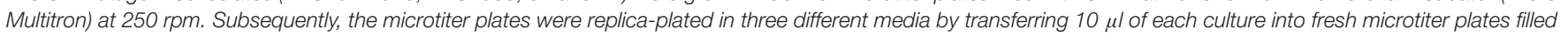

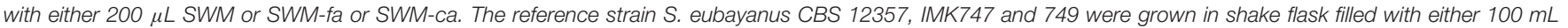

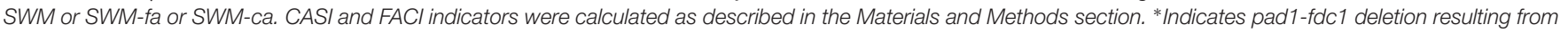
UV mutagenesis. 


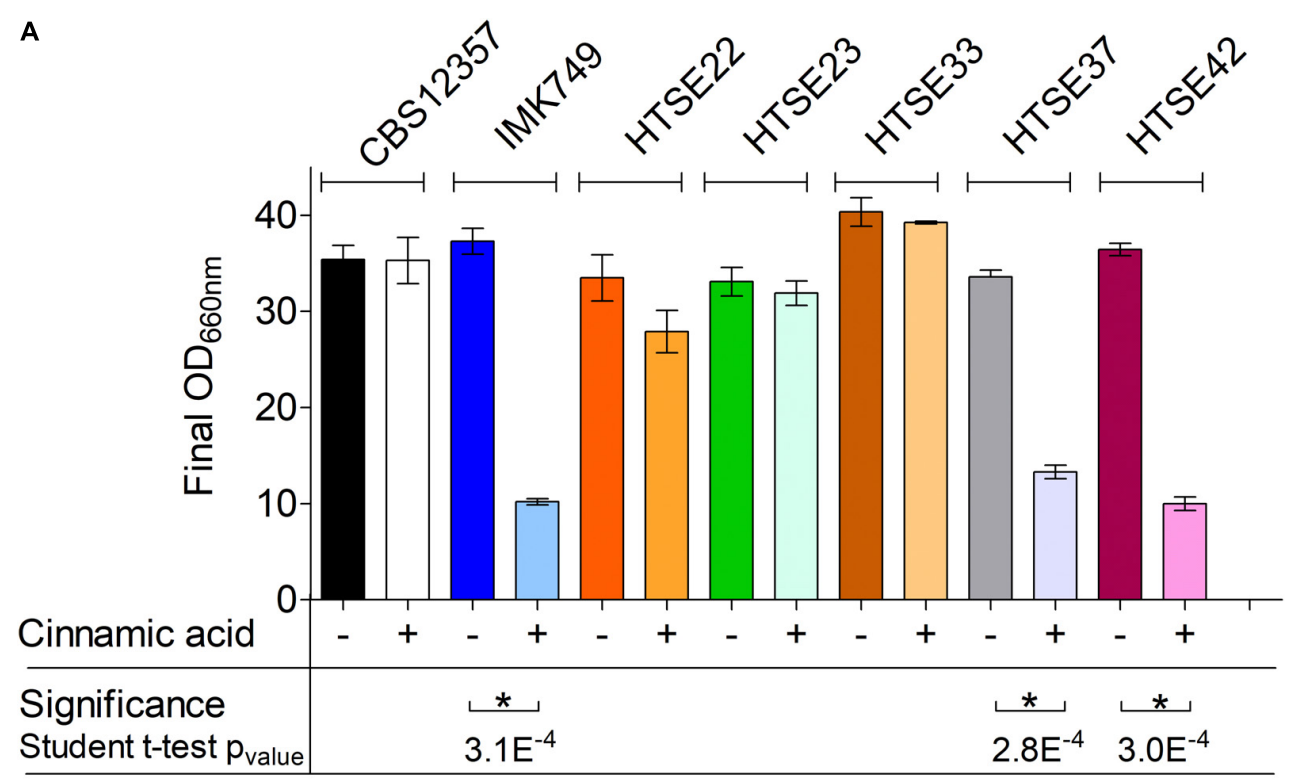

B

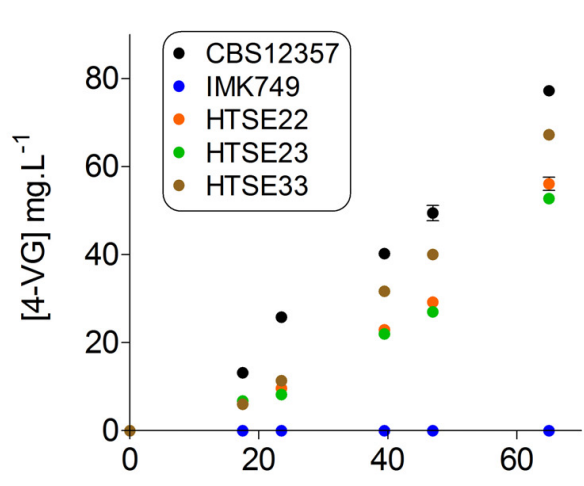

D

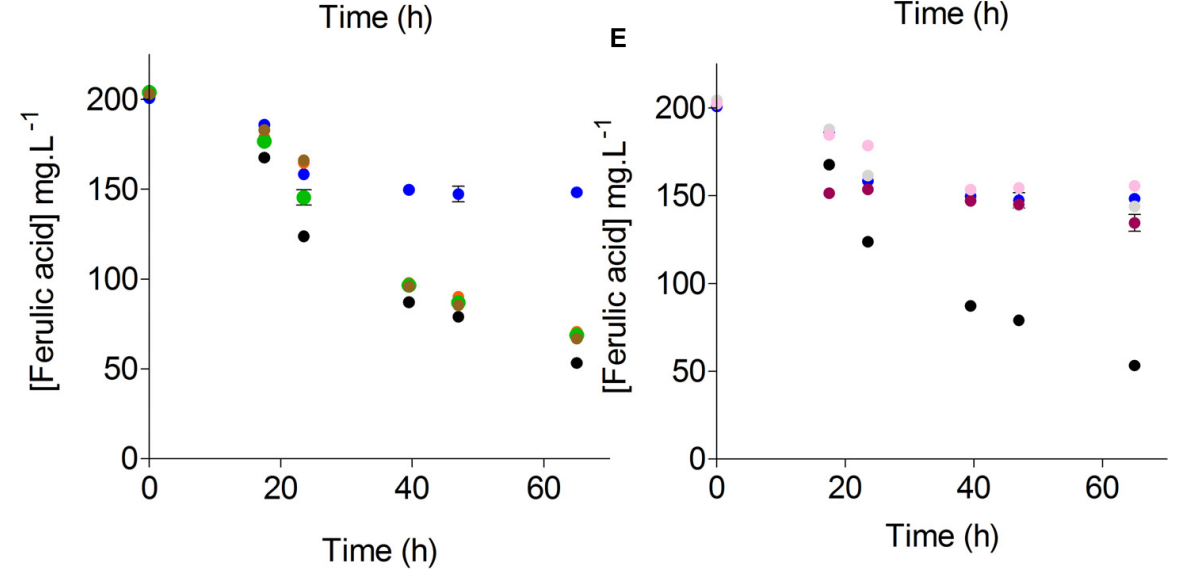

C

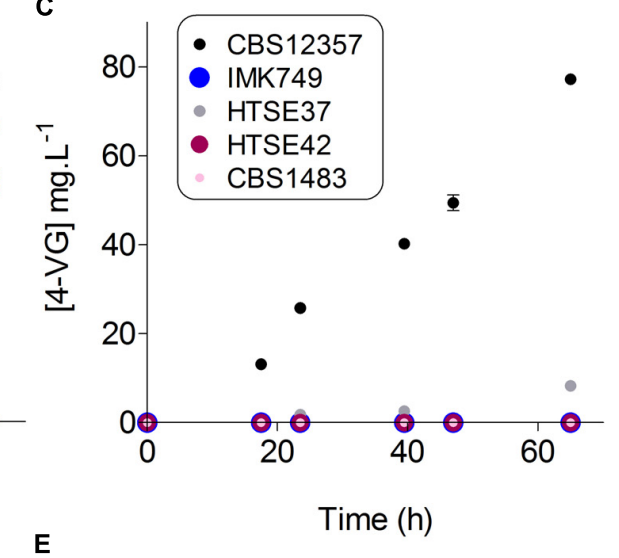


culture served to inoculate three different media. SWM and SWM-ca (1 mM cinnamic acid) cultures were used to assess the CASI. The third culture (SWM-fa) was used to measure FACI by measuring the UV-Vis absorption spectrum of the culture supernatants. A total of ca. 1000 mutagenized colonies were tested (Figure 4B) and data points including growth on SWM and SMW-ca approximated by $\mathrm{OD}_{660 \mathrm{~nm}}$ after $72 \mathrm{~h}$ of cultivation, discrete UV-Vis absorbance ranged from at $280-380 \mathrm{~nm}$ with $10 \mathrm{~nm}$ intervals of SMW-fa culture supernatant after $72 \mathrm{~h}$ of cultivation were statistically evaluated by PCA (Figure 4B). Three groups were pre-labeled in this analysis, (i) the first one included replicates $(n=80)$ of the parental strain CBS 12357 (in green Figure 4B), (ii) the second include blank cultures $(n=80)$ (in blue Figure 4B) and (iii) the third group included variants exhibiting a pronounced growth defect on SMW defined by an $\mathrm{OD}_{660 \mathrm{~nm}}$ after $72 \mathrm{~h} 25 \%$ lower that the average growth $\left(\mathrm{OD}_{660 \mathrm{~nm}}\right.$ at $72 \mathrm{~h}$ ) of CBS 12357 (in red Figure 4B). By selecting the first two components that together explained more than $95 \%$ of the data variance, the variants formed a group distinct from the parental CBS 12357 strain group revealing the difference in preculture conditions between the parental strain and the UV mutagenized variants. The poor growing cell lines were spread over three quadrants. Although not clearly forming a centered group, about fifty UV strains were separated in the bottom right quadrant. Five different UV mutagenized variants from that quadrant were selected two exhibited CASI and FACI scores comparable to S. eubayanus IMK749 $\left(\mathrm{CASI}^{\mathrm{IMK} 749}=72.7\right.$ and FACI $\left.^{\mathrm{IMK} 749}=15.7\right)$ while the other three showed deviation from IMK749 values (indicated in yellow Figure $4 \mathbf{B}$ and Table 3 ). As comparison, wild type CBS 12357 which converts ferulic acid into $4-\mathrm{VG}$, had a CASI value of 0.1 and a FACI of 73 . The five mutagenized variants exhibited CASI higher than 5 and FACI value ranged between 60 (for HTSE022) and 15 (for HTSE037 and HTSE042).

\section{Characterization of S. eubayanus Strains With a Reduced Ability to Produce 4-VG}

The set of five selected S. eubayanus CBS 12357 variants was compared to the parental S. eubayanus CBS12537 and the control PAD1-FDC1 deletion strains $S$. eubayanus IMK747 (MATa/MATaSepad1-Sefdc1 $\triangle$ ::amdSYM/SePAD1SeFDC1) and $S$. eubayanus IMK749 (MATa/MAT $\alpha$ Sepad1-Sefdc1 $\Delta$ ::amdSYM/Sepad1-Sefdc1 $\Delta::$ amdSYM) in shake flask cultures. Three of the selected variants HTSE022, HTSE023 and HTSE033 did not show significant cinnamic acid inhibition relative to the parental strain CBS 12357 (MATa/MATa SePAD1-SeFDC1/ SePAD1-SeFDC1) and IMK747 (MATa/MATa Sepad1-Sefdc1 $\triangle$ :::amdSYM/SePAD1-SeFDC1). This confirmed that the values measured in the screening could be benchmarked to the those of the controls CBS 12357 and IMK747. Conversely, variants HTSE037 and HTSE042 showed strong and significant growth inhibition (Student's $t$-test $p$-value $=2.8 \mathrm{E}^{-4}$ and $3.0 \mathrm{E}^{-4}$ respectively) compared to the parental strain CBS 12357 . These data were highly comparable

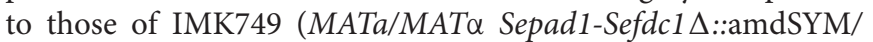
Sepad1-Sefdc1 $\Delta::$ amdSYM) (Figure 5A).

In line with the toxicity assay, the selected variants HTSE022, HTSE023 and HTSE033 showed formation of 4-VG comparable to that of the parental strain S. eubayanus CBS 12357 (Figure 5B). Further corroborating the toxicity assay results, the variants HTSE037 and HTSE042 did not convert ferulic acid into 4-VG,

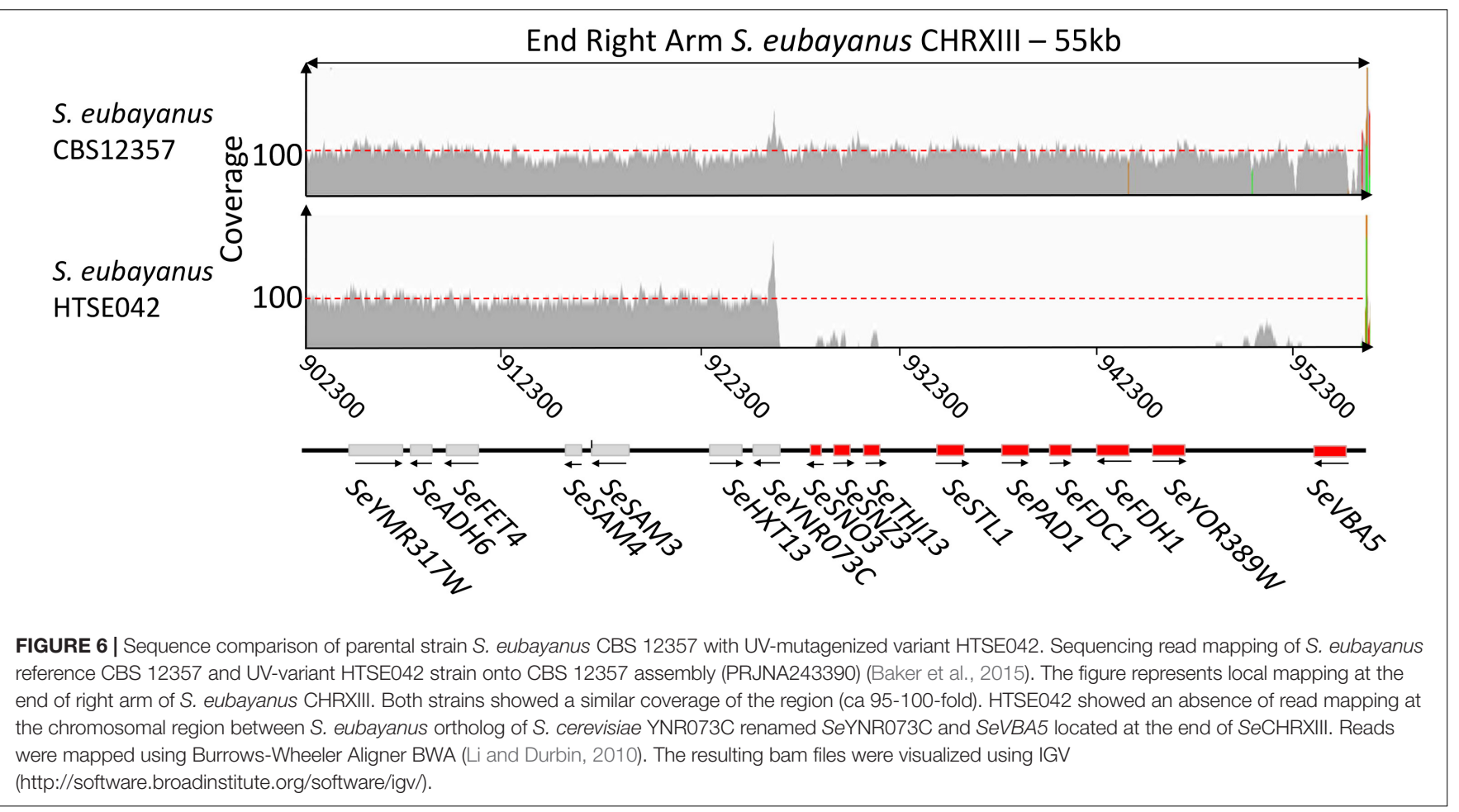


a result that perfectly matched the performance of the double PAD1-FDC1 knockout IMK749 (Figure 5B).

\section{Genome Sequence Analysis}

Out of the two Pof ${ }^{-}$selected variants, HTSE042 exhibited the best performance. While HTSE037 showed an significant reduction of produced 4 -VG (Student's $t$-test-value $=5.8 \mathrm{E}^{-6}$, Figures $5 \mathbf{A}, \mathbf{B}$ ), a low amount could still be detected, this was contrasting with the complete absence of 4-VG detection in HTSE042, therefore S. eubayanus variant HTSE042 was whole genome sequenced and compared to the parental strain S. eubayanus CBS 12357 genome assembly. Single-nucleotide variations and indels were determined using Pilon (Walker et al., 2014) and visualized using $\mathrm{IGV}^{6}$. Only 39 single nucleotide variations (SNV) were detected in HTSE042 sequence relative to CBS 12357. Theses SNV were distributed in coding regions for three of them and the remaining 36 were located in intergenic regions (at least 1 $\mathrm{kb}$ upstream and downstream of a coding sequence). Out of the three mutations within coding sequences only one resulted in an amino acid change (SePST1, G-225-S), the other two mutations in RSP5 and SUN4 were synonymous mutations. However, the most severe and relevant mutation was a large deletion observed toward the right telomere of chromosome XIII. A region of

${ }^{6} \mathrm{http}: / /$ software.broadinstitute.org/software/igv/

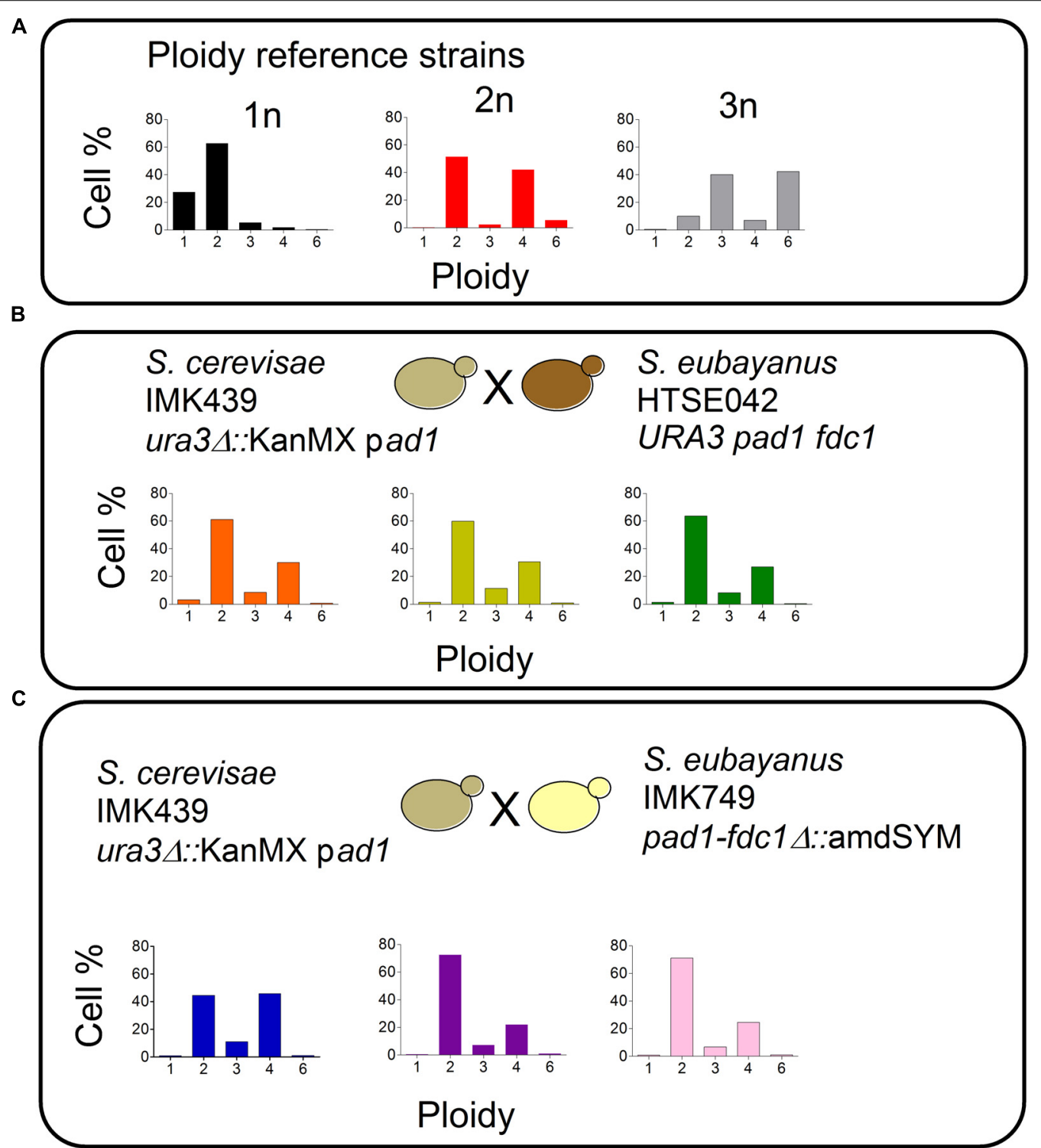

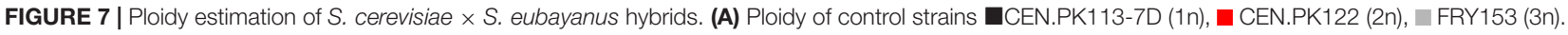
(B) Ploidy estimation of S. cerevisiae (IMK439) $\times$ S. eubayanus (HTSE042) hybrids $\mathrm{HTSH009,}$ HTSH010 and $\mathbf{H T S H 0 1 1}$. (C) Ploidy estimation of S. cerevisiae (IMK439) × S. eubayanus (IMK749) hybrids HTSH012, HTSH013 and HTSH014. Cells were stained with SYTOX Green Nucleic Acid and analyzed on a flow cytometer equipped with a $488 \mathrm{~nm}$ laser. 
approximately $27 \mathrm{~kb}$ was deleted in HTSE042 (Figure 6). This region harbored the genes SePAD1 and SeFDC1. This is in contrast to the location of PAD1-FDC1 in S. cerevisiae where the two genes are positioned close to the subtelomeric region of chromosome IV right arm.

\section{Characterization of Hybrids With a Reduced Capacity to Produce 4-VG}

Saccharomyces pastorianus strains are hybrids of $S$. cerevisiae and $S$. eubayanus parents. Therefore to form de novo hybrids, the screened Pof ${ }^{-}$S. eubayanus variant HTSE042 was crossed with the $S$. cerevisiae strain IMK049. This strain derived from the CEN.PK lineage carried a non-functional PAD1 allele (Otero et al., 2010; Nijkamp et al., 2012; Salazar et al., 2017). In addition to the absence of $4-\mathrm{VG}$ negative ( $\mathrm{Pof}^{-}$) phenotype and to ease the selection of the constructed hybrids, $S$. cerevisiae IMK439 was also carrying a ura3 $\Delta$ allele interrupted by a KanMX cassette conferring resistance to G418 (ura3 $\Delta::$ KanMX). Mass mating (Hawthorne and Philippsen, 1994) between spores of S. eubayanus HTSE042 and cells of S. cerevisiae IMK439 was performed for $5 \mathrm{~h}$ at $30^{\circ} \mathrm{C}$. The mating mixture was then plated on minimal medium containing G418 (SMUG). The selection of true hybrids was based on their uracil prototrophy and G418 resistance, contributed by the S. eubayanus and S. cerevisiae parents, respectively. Based on specific typing PCR able to discriminate $S$. cerevisiae and $S$. eubayanus species, and ploidy determination by flow cytometry (Figure 7), three hybrid isolates were selected and named HTSH009, HTSH010, and HTSH011. In order to benchmark the performance of HTSH009 to 011, hybrids between S. cerevisiae IMK439 and S. eubayanus IMK749 that carried a deletion of FDC1-PAD1 were also constructed and similarly three characterized hybrids renamed HTSH012 to 014 were selected. These six newly constructed hybrids were additionally compared to IMS0408 a diploid hybrid made from S. eubayanus CBS 12357 the parent of HTSE042 and IMK749 and S. cerevisiae IMK439 (Hebly et al., 2015).

To validate the strategy, the hybrids labeled HTSH009 to 014 were grown in SWM-fa under micro aerobic conditions at $12^{\circ} \mathrm{C}$ and sugar consumption, ethanol production ferulic acid and $4-\mathrm{VG}$ production were measured (Figure 8). As previously shown, the S. eubayanus CBS 12357 strain did not consume maltotriose (Hebly et al., 2015; Krogerus et al., 2015). This phenotype was logically shared with the IMK749 and HTSE042 strains. The parental S. cerevisiae strain IMK439 auxotrophic for uracil expectedly did not grow on SWM-fa medium. Interestingly, all newly constructed hybrids grew faster than their parents and the hybrid IMS0408. They also grew to higher $\mathrm{OD}_{660 \mathrm{~nm}}$, this was related to the capacity of the hybrids (HTSH009-014 and IMS0408) to consume all sugars including maltotriose present in the culture resulting in a significant increase $\left(+25 \%\right.$, Student $t$-test $p$-value $\left.=2.19 \mathrm{E}^{-05}\right)$ in ethanol concentration at the end of the fermentation. But no significant differences were observed between the three groups of constructed hybrids regarding growth kinetics and ethanol production but conversely, the difference in $4-\mathrm{VG}$ was significant between the hybrid groups. The hybrid between wildtype S. eubayanus CBS 12357 and S. cerevisiae IMK439, IMS0408 (Hebly et al., 2015) consumed ferulic acid and converted it to 4-VG stoichiometrically (Figure 8). The hybrids issued from the mating of either S. eubayanus IMK749 or HTSE042 were not distinguishable and exhibited a complete absence of 4-VG synthesis (Figures 8, 9). These results demonstrated the applicability of the UV-mutagenized Pof $^{-}$variant to construct de novo hybrids holding phenotypes potentially relevant for the brewing industry.

\section{DISCUSSION}

The results reported in this study described a methodology to successfully construct Pof $^{-}$strains which turned out to be valuable to generate de novo $S$. pastorianus interspecies hybrids (Nakao et al., 2009; van den Broek et al., 2015). While 4-vinylguaiacol (4-VG) and 4-vinylphenol (4-VP) are of key importance in top-fermented wheat beers, this distinctive clove-like and phenolic aroma is highly undesired in lager beers. Compared to other classes of flavor molecules found in beverages, 4-VG exhibits a lower sensory threshold value, reported to be $0.3 \mathrm{mg} \cdot \mathrm{L}^{-1}$ (Vanbeneden et al., 2007) and the typical concentration conveying a pleasant aroma in wheat

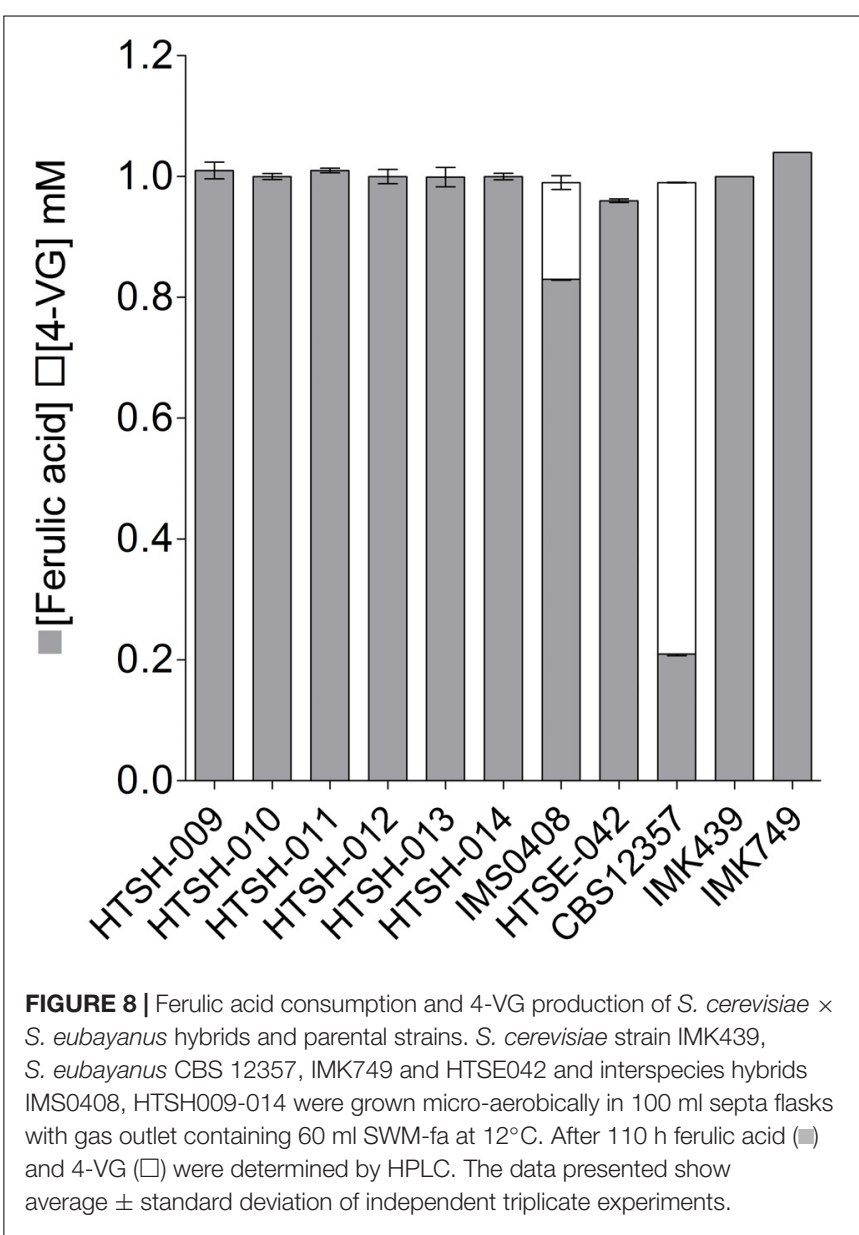




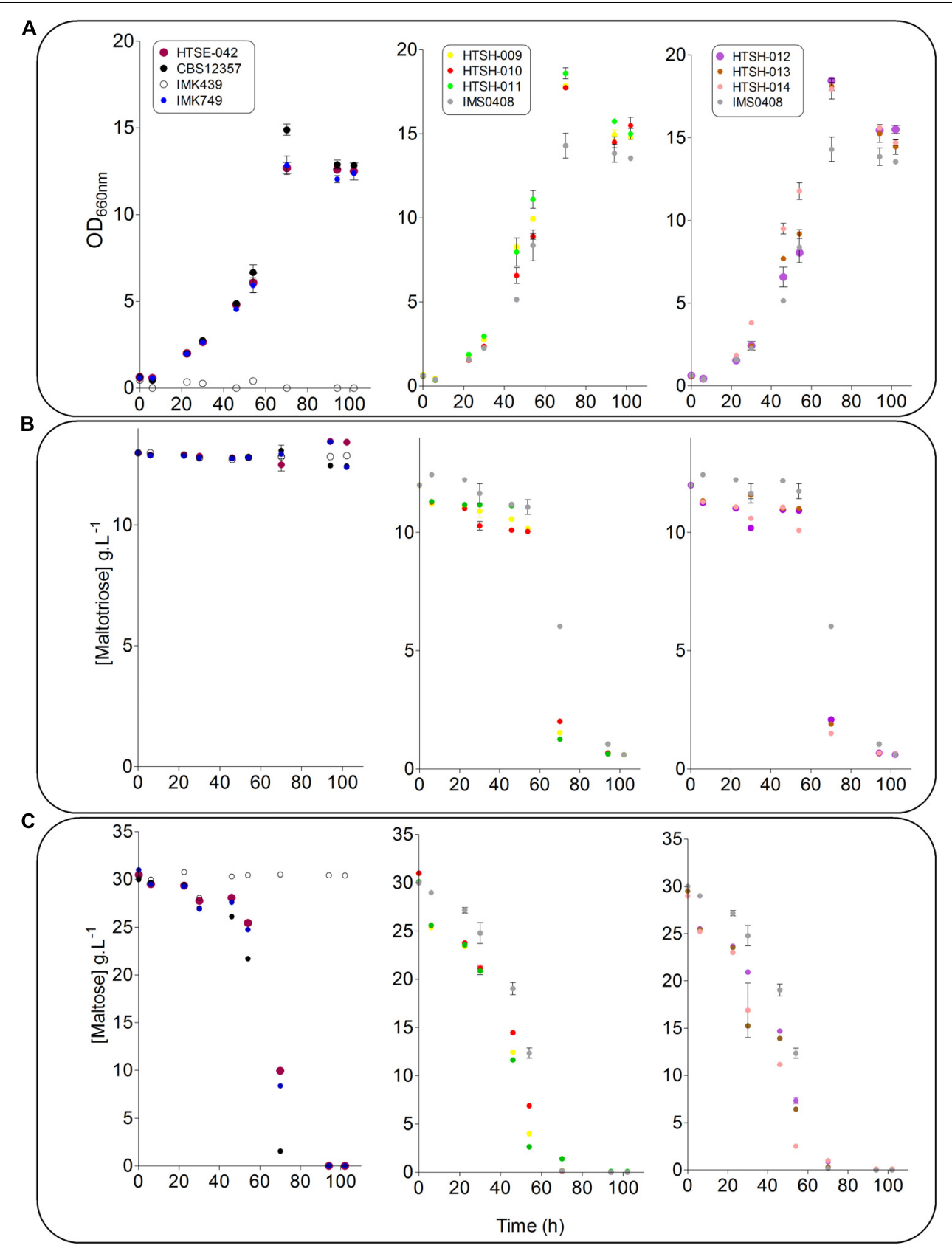

FIGURE 9 | Fermentation performance of S. cerevisiae $\times$ S. eubayanus hybrids and parental control strains. S. cerevisiae strain IMK439 (O), S. eubayanus CBS

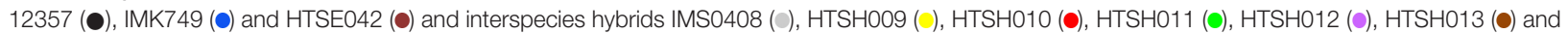
$\mathrm{HTSH014} \mathrm{(0)} \mathrm{were} \mathrm{grown} \mathrm{micro-aerobically} \mathrm{in} 100 \mathrm{ml}$ septa flasks with gas outlet containing $60 \mathrm{ml} \mathrm{SWM-fa} \mathrm{at} 12^{\circ} \mathrm{C}$. OD $660 \mathrm{~nm}$ (A), maltotriose (B) and maltose (C) were measured regularly for $110 \mathrm{~h}$. The data presented show average \pm standard deviation of independent triplicate experiments.

beer ranges from 2 to $3.5 \mathrm{mg} \cdot \mathrm{L}^{-1}$. Above $4 \mathrm{mg} \cdot \mathrm{L}^{-1}, 4-\mathrm{VG}$ negatively affects the bouquet of top-fermented wheat beers. Consequently, low concentrations of 4 -VG might modify or hide the perception of other flavors and might compromise development of beverage products with innovative and more diverse aroma profiles (Gallone et al., 2016). Therefore availability of yeast strains not only reduced but devoid of their ability to produce $4-\mathrm{VG}$ would be seen as valuable asset in mating programs. Although, the biochemistry of the 4-VG formation is well understood, implementation of mutation leading to deletion/interruption of either PAD1 or FDC1 or both genes by targeted genetic engineering [e.g., CRISPR genome editing (de Vries et al., 2017)] cannot be envisaged in the context of beverage production (Varzakas et al., 2007; Twardowski and Malyska, 2015). Traditionally food and beverage industries relied on induction of random mutations by chemical or physical 
mutagens (Giudici et al., 2005), evolutionary engineering (Ekberg et al., 2013; Brickwedde et al., 2017) and mating approaches (Steensels et al., 2014; Hebly et al., 2015; Magalhaes et al., 2017) and subsequent selection of phenotypically improved lineages. As often quoted the first law of screening 'you get what you screen for' associates the importance of the assays accuracy relative to the screening targets. To warrant the selection of true positive candidates, two complementary assays were used in this study. The cinnamic acid sensitivity assay served two purposes, (i) to exclude strains with fitness reduction and (ii) select for variants responding negatively to weak acid stress, a trait that hypothetically could reflect an impaired detoxification via decarboxylation. The second test assessed qualitatively the ferulic acid conversion in 4-VG. The quantification of proxy value as CASI and FACI values (Figure 3) enabled to rank and select mutagenized colonies that had conserved sufficient growth with reduced 4-VG biosynthesis and therefore from a very early stage limit testing false positives. The value and efficiency of this bimodal screening approach was illustrated by the high selection yield of true positive variants. Typically a mutagenesis and screening program would encompass testing of a large population of cells that should in theory be proportional to the genome gene density and size. It is not exaggerated to have to screen populations of size ranging from 6,000 to 20,000 mutagenized yeast isolates to find a hand full of potential variants. The 4VG negative screening proved to be extremely sensitive as two Pof $^{-}$variants were accurately sorted in the first screening level within a crowd of only ca. 2000 mutagenized colonies. With such efficiency transferring this phenotypic trait to other S. eubayanus strains and further to other yeast that might be used in mating approaches would be realistic. Hitherto most hybridization involving $S$. eubayanus rested on the use of the strain CBS 12357 originating from Patagonia (Libkind et al., 2011). Since its first isolation by Libkind et al. (2011) S. eubayanus has been isolated on several continents (Bing et al., 2014; Peris et al., 2014; Gayevskiy and Goddard, 2016) but so far the information about these isolates remains limited, however inspection of available genome sequences confirmed the presence of the two genes PAD1

\section{REFERENCES}

Abdulovic, A. L., and Jinks-Robertson, S. (2006). The in Vivo characterization of translesion synthesis across UV-induced lesions in Saccharomyces cerevisiae:

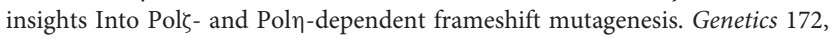
1487-1498. doi: 10.1534/genetics.105.052480

Baker, E., Wang, B., Bellora, N., Peris, D., Hulfachor, A. B., Koshalek, J. A., et al. (2015). The genome sequence of Saccharomyces eubayanus and the domestication of lager-brewing yeasts. Mol. Biol. Evol. 32, 2818-2831. doi: 10.1093/molbev/msv168

Baranowski, J. D., Davidson, P. M., Nagel, C. W., and Branen, A. L. (1980). Inhibition of Saccharomyces cerevisiae by naturally occuring hydroxycinnamates. J. Food Sci. 45, 592-594. doi: 10.1111/j.1365-2621. 1980.tb04107.x

Bhuiya, M. W., Lee, S. G., Jez, J. M., and Yu, O. (2015). Structure and mechanism of ferulic acid decarboxylase (FDC1) from Saccharomyces cerevisiae. Appl. Environ. Microbiol. 81, 4216-4223. doi: 10.1128/AEM.00762-15

Bing, J., Han, P. J., Liu, W. Q., Wang, Q. M., and Bai, F. Y. (2014). Evidence for a far east Asian origin of lager beer yeast. Curr. Biol. 24, R380-R381. doi: 10.1016/j.cub.2014.04.031 and FDC1 suggesting that these isolates would be able to produce 4-VG. This approach could even be applied to Saccharomyces cerevisiae strains and more specifically on wild type isolates which have not yet lost the $\mathrm{Pof}^{+}$trait under domestication evolutionary pressure (Gallone et al., 2016). Eventually, the approach could be applied on different Saccharomyces species known to harbor PAD1 and FDC1 orthologs as S. paradoxus, S. kudriavzevii, and S. mikatae.

The Pof $^{-}$S. cerevisiae $\times S$. eubayanus hybrids described in this study were not the first to be reported. But contrasting with the rational design developed here, the precedent examples described Pof ${ }^{-}$phenotypes that related to heterosis or hybrid vigor since Pof $^{-}$offspring were resulting from crosses involving $\mathrm{Pof}^{+}$parents. These specific hybrids expressed a dominant Pof $^{-}$ phenotype not yet completely understood in the context of these works. While it was not possible to exclude that the phenotype might still be linked to randomly occurring non-sense mutations in the PAD1 and FDC1 genes, it demonstrated that selection of Pof $^{-}$hybrids remained to a large extent accidental. The results reported in this work further emphasized the importance of a systematic methodology to easily and meticulously generate parental Pof ${ }^{-}$parental strains that would significantly contribute to intensification of de novo lager yeast hybridization program.

\section{AUTHOR CONTRIBUTIONS}

JD, SW, JP, and J-MD designed the experiments. JD, SW, MB, and J-MD critically analyzed the results. JD and SW performed the experiments. JD and J-MD wrote the manuscript. All authors read and approved the final manuscript.

\section{ACKNOWLEDGMENTS}

We are thankful to Dr. Niels Kuijpers and Dr. Jan-Maarten Geertman (HEINEKEN Supply Chain B.V.) for their support during this project and their critical reading of the manuscript.

Bourne, L., Paganga, G., Baxter, D., Hughes, P., and Rice-Evans, C. (2000). Absorption of ferulic acid from low-alcohol beer. Free Radic. Res. 32, 273-280. doi: 10.1080/10715760000300281

Brickwedde, A., van den Broek, M., Geertman, J. A., Magalhaes, F., Kuijpers, N. G. A., Gibson, B., et al. (2017). Evolutionary engineering in chemostat cultures for improved maltotriose fermentation kinetics in Saccharomyces pastorianus lager brewing yeast. Front. Microbiol. 8:1690. doi: 10.3389/fmicb. 2017.01690

Clausen, M., Lamb, C. J., Megnet, R., and Doerner, P. W. (1994). PAD1 encodes phenylacrylic acid decarboxylase which confers resistance to cinnamic acid in Saccharomyces cerevisiae. Gene 142, 107-112. doi: 10.1016/0378-1119(94) 90363-8

Coghe, S., Benoot, K., Delvaux, F., Vanderhaegen, B., and Delvaux, F. R. (2004). Ferulic acid release and 4-vinylguaiacol formation during brewing and fermentation: indications for feruloyl esterase activity in Saccharomyces cerevisiae. J. Agric. Food Chem. 52, 602-608. doi: 10.1021/jf03 46556

de Vries, A. R., de Groot, P. A., van den Broek, M., and Daran, J. G. (2017). CRISPRCas9 mediated gene deletions in lager yeast Saccharomyces pastorianus. Microb. Cell Fact. 16:222. doi: 10.1186/s12934-017-0835-1 
DiCarlo, J. E., Norville, J. E., Mali, P., Rios, X., Aach, J., and Church, G. M. (2013). Genome engineering in Saccharomyces cerevisiae using CRISPR-Cas systems. Nucleic Acids Res. 41, 4336-4343. doi: 10.1093/nar/gkt135

Doudna, J. A., and Charpentier, E. (2014). The new frontier of genome engineering with CRISPR-Cas9. Science 346:1258096. doi: 10.1126/science.1258096

Duetz, W. A., Ruedi, L., Hermann, R., O’Connor, K., Buchs, J., and Witholt, B. (2000). Methods for intense aeration, growth, storage, and replication of bacterial strains in microtiter plates. Appl. Environ. Microbiol. 66, 2641-2646. doi: 10.1128/AEM.66.6.2641-2646.2000

Dykes, L., and Rooney, L. W. (2007). Phenolic compounds in cereal grains and their health benefits. Cereal Foods World 52, 105-111. doi: 10.1094/cfw-52-3-0105

Ekberg, J., Rautio, J., Mattinen, L., Vidgren, V., Londesborough, J., and Gibson, B. R. (2013). Adaptive evolution of the lager brewing yeast Saccharomyces pastorianus for improved growth under hyperosmotic conditions and its influence on fermentation performance. FEMS Yeast Res. 13, 335-349. doi: $10.1111 / 1567-1364.12038$

Entian, K.-D., and Kötter, P. (2007). "25 Yeast genetic strain and plasmid collections," in Methods in Microbiology, eds I. Stansfield and M. J. R. Stark (Cambridge, MA: Academic Press), 629-666.

Gallone, B., Steensels, J., Prahl, T., Soriaga, L., Saels, V., Herrera-Malaver, B., et al. (2016). Domestication and divergence of Saccharomyces cerevisiae beer yeasts. Cell 166:e1316. doi: 10.1016/j.cell.2016.08.020

Gayevskiy, V., and Goddard, M. R. (2016). Saccharomyces eubayanus and Saccharomyces arboricola reside in North Island native New Zealand forests. Environ. Microbiol. 18, 1137-1147. doi: 10.1111/1462-2920. 13107

Gietz, R. D., and Schiestl, R. H. (2007). High-efficiency yeast transformation using the LiAc/SS carrier DNA/PEG method. Nat. Protoc. 2, 31-34. doi: 10.1038/ nprot.2007.13

Giudici, P., Solieri, L., Pulvirenti, A. M., and Cassanelli, S. (2005). Strategies and perspectives for genetic improvement of wine yeasts. Appl. Microbiol. Biotechnol. 66, 622-628. doi: 10.1007/s00253-004-1784-2

Gonzalez-Ramos, D., van den Broek, M., van Maris, A. J. A., Pronk, J. T., and Daran, J. M. G. (2013). Genome-scale analyses of butanol tolerance in Saccharomyces cerevisiae reveal an essential role of protein degradation. Biotechnol. Biofuels 6:48. doi: 10.1186/1754-6834-6-48

Haase, S. B., and Reed, S. I. (2002). Improved flow cytometric analysis of the budding yeast cell cycle. Cell Cycle 1, 132-136. doi: 10.4161/cc.1.2.114

Hashimoto, S., Ogura, M., Aritomi, K., Hoshida, H., Nishizawa, Y., and Akada, R. (2005). Isolation of auxotrophic mutants of diploid industrial yeast strains after UV mutagenesis. Appl. Environ. Microbiol. 71, 312-319. doi: 10.1128/AEM.71. 1.312-319.2005

Hawthorne, D., and Philippsen, P. (1994). Genetic and molecular analysis of hybrids in the genus Saccharomyces involving S. cerevisiae, S. uvarum and a new species, S. douglasii. Yeast 10, 1285-1296. doi: 10.1002/yea.3201 01005

Hazelwood, L. A., Tai, S. L., Boer, V. M., de Winde, J. H., Pronk, J. T., and Daran, J. M. (2006). A new physiological role for Pdr12p in Saccharomyces cerevisiae: export of aromatic and branched-chain organic acids produced in amino acid catabolism. FEMS Yeast Res. 6, 937-945. doi: 10.1111/j.1567-1364.2006.00094.x

Hebly, M., Brickwedde, A., Bolat, I., Driessen, M. R., de Hulster, E. A., van den Broek, M., et al. (2015). S. cerevisiae $\times$ S. eubayanus interspecific hybrid, the best of both worlds and beyond. FEMS Yeast Res. 15:fov005. doi: 10.1093/femsyr/ fov005

Huang, H. K., Chen, L. F., Tokashiki, M., Ozawa, T., Taira, T., and Ito, S. (2012). An endogenous factor enhances ferulic acid decarboxylation catalyzed by phenolic acid decarboxylase from Candida guilliermondii. AMB Express 2:4. doi: 10.1186/ 2191-0855-2-4

Jakociunas, T., Jensen, M. K., and Keasling, J. D. (2016). CRISPR/Cas9 advances engineering of microbial cell factories. Metab. Eng. 34, 44-59. doi: 10.1016/j. ymben.2015.12.003

Jinek, M., Chylinski, K., Fonfara, I., Hauer, M., Doudna, J. A., and Charpentier, E. (2012). A programmable dual-RNA-guided DNA endonuclease in adaptive bacterial immunity. Science 337, 816-821. doi: 10.1126/science.1225829

Koopman, F., Beekwilder, J., Crimi, B., van Houwelingen, A., Hall, R. D., Bosch, D., et al. (2012). De novo production of the flavonoid naringenin in engineered Saccharomyces cerevisiae. Microb. Cell Fact. 11:155. doi: 10.1186/1475-285911-155
Krogerus, K., Arvas, M., De Chiara, M., Magalhaes, F., Mattinen, L., Oja, M., et al. (2016). Ploidy influences the functional attributes of de novo lager yeast hybrids. Appl. Microbiol. Biotechnol. 100, 7203-7222. doi: 10.1007/s00253-016-7588-3

Krogerus, K., Magalhaes, F., Vidgren, V., and Gibson, B. (2015). New lager yeast strains generated by interspecific hybridization. J. Ind. Microbiol. Biotechnol. 42, 769-778. doi: 10.1007/s10295-015-1597-6

Krogerus, K., Magalhaes, F., Vidgren, V., and Gibson, B. (2017a). Novel brewing yeast hybrids: creation and application. Appl. Microbiol. Biotechnol. 101, 65-78. doi: 10.1007/s00253-016-8007-5

Krogerus, K., Seppanen-Laakso, T., Castillo, S., and Gibson, B. (2017b). Inheritance of brewing-relevant phenotypes in constructed Saccharomyces cerevisiae $\times$ Saccharomyces eubayanus hybrids. Microb. Cell Fact. 16:66. doi: 10.1186/ s12934-017-0679-8

Kuijpers, N. G., Solis-Escalante, D., Luttik, M. A., Bisschops, M. M., Boonekamp, F. J., van den Broek, M., et al. (2016). Pathway swapping: toward modular engineering of essential cellular processes. Proc. Natl. Acad. Sci. U.S.A. 113, 15060-15065. doi: 10.1073/pnas.1606701113

Larsson, S., Nilvebrant, N. O., and Jonsson, L. J. (2001). Effect of overexpression of Saccharomyces cerevisiae Padlp on the resistance to phenylacrylic acids and lignocellulose hydrolysates under aerobic and oxygen-limited conditions. Appl. Microbiol. Biotechnol. 57, 167-174. doi: 10.1007/s002530100742

Li, H., and Durbin, R. (2010). Fast and accurate long-read alignment with BurrowsWheeler transform. Bioinformatics 26, 589-595. doi: 10.1093/bioinformatics/ btp698

Li, H., Handsaker, B., Wysoker, A., Fennell, T., Ruan, J., Homer, N., et al. (2009). The sequence alignment/map format and SAMtools. Bioinformatics 25, 2078-2079. doi: 10.1093/bioinformatics/btp352

Libkind, D., Hittinger, C. T., Valerio, E., Goncalves, C., Dover, J., Johnston, M., et al. (2011). Microbe domestication and the identification of the wild genetic stock of lager-brewing yeast. Proc. Natl. Acad. Sci. U.S.A. 108, 14539-14544. doi: 10.1073/pnas.1105430108

Lin, F., Ferguson, K. L., Boyer, D. R., Lin, X. N., and Marsh, E. N. (2015). Isofunctional enzymes PAD1 and UbiX catalyze formation of a novel cofactor required by ferulic acid decarboxylase and 4-hydroxy-3-polyprenylbenzoic acid decarboxylase. ACS Chem. Biol. 10, 1137-1144. doi: 10.1021/cb5008103

Looke, M., Kristjuhan, K., and Kristjuhan, A. (2011). Extraction of genomic DNA from yeasts for PCR-based applications. Biotechniques 50, 325-328. doi: $10.2144 / 000113672$

Magalhaes, F., Krogerus, K., Vidgren, V., Sandell, M., and Gibson, B. (2017). Improved cider fermentation performance and quality with newly generated Saccharomyces cerevisiae $\times$ Saccharomyces eubayanus hybrids. J. Ind. Microbiol. Biotechnol. 44, 1203-1213. doi: 10.1007/s10295-017-1947-7

Mans, R., van Rossum, H. M., Wijsman, M., Backx, A., Kuijpers, N. G. A., van den Broek, M., et al. (2015). CRISPR/Cas9: a molecular Swiss army knife for simultaneous introduction of multiple genetic modifications in Saccharomyces cerevisiae. FEMS Yeast Res. 15:fov004. doi: 10.1093/femsyr/fov004

McKenna, R., Thompson, B., Pugh, S., and Nielsen, D. R. (2014). Rational and combinatorial approaches to engineering styrene production by Saccharomyces cerevisiae. Microb. Cell Fact. 13:123. doi: 10.1186/s12934-0140123-2

McMurrough, I., Madigan, D., Donnelly, D., Hurley, J., Doyle, A. M., Hennigan, G., et al. (1996). Control of ferulic acid and 4-vinyl guaiacol in brewing. J. Inst. Brew. 102, 327-332. doi: 10.1002/j.2050-0416.1996.tb00918.x

Meaden, P. G., and Taylor, N. R. (1991). Cloning of a yeast gene which causes phenolic off-flavours in beer. J. Inst. Brew. 97, 353-357. doi: 10.1002/j.20500416.1991.tb01075.x

Mertens, S., Steensels, J., Saels, V., De Rouck, G., Aerts, G., and Verstrepen, K. J. (2015). A large set of newly created interspecific Saccharomyces hybrids increases aromatic diversity in lager beers. Appl. Environ. Microbiol. 81, 8202-8214. doi: 10.1128/aem.02464-15

Mollapour, M., Fong, D., Balakrishnan, K., Harris, N., Thompson, S., Schuller, C., et al. (2004). Screening the yeast deletant mutant collection for hypersensitivity and hyper-resistance to sorbate, a weak organic acid food preservative. Yeast 21, 927-946. doi: 10.1002/yea.1141

Mukai, N., Masaki, K., Fujii, T., Kawamukai, M., and Iefuji, H. (2010). PAD1 and FDC1 are essential for the decarboxylation of phenylacrylic acids in Saccharomyces cerevisiae. J. Biosci. Bioeng. 109, 564-569. doi: 10.1016/j.jbiosc. 2009.11.011 
Nakao, Y., Kanamori, T., Itoh, T., Kodama, Y., Rainieri, S., Nakamura, N., et al. (2009). Genome sequence of the lager brewing yeast, an interspecies hybrid. DNA Res. 16, 115-129. doi: 10.1093/dnares/dsp003

Nijkamp, J. F., van den Broek, M., Datema, E., de Kok, S., Bosman, L., Luttik, M. A., et al. (2012). De novo sequencing, assembly and analysis of the genome of the laboratory strain Saccharomyces cerevisiae CEN.PK113-7D, a model for modern industrial biotechnology. Microb. Cell Fact. 11:36. doi: 10.1186/14752859-11-36

Okuno, M., Kajitani, R., Ryusui, R., Morimoto, H., Kodama, Y., and Itoh, T. (2016). Next-generation sequencing analysis of lager brewing yeast strains reveals the evolutionary history of interspecies hybridization. DNA Res. 23, 67-80. doi: 10.1093/dnares/dsv037

Otero, J. M., Vongsangnak, W., Asadollahi, M. A., Olivares-Hernandes, R., Maury, J., Farinelli, L., et al. (2010). Whole genome sequencing of Saccharomyces cerevisiae: from genotype to phenotype for improved metabolic engineering applications. BMC Genomics 11:723. doi: 10.1186/1471-2164$11-723$

Pengelly, R. J., and Wheals, A. E. (2013). Rapid identification of Saccharomyces eubayanus and its hybrids. FEMS Yeast Res. 13, 156-161. doi: 10.1111/15671364.12018

Peris, D., Sylvester, K., Libkind, D., Goncalves, P., Sampaio, J. P., Alexander, W. G., et al. (2014). Population structure and reticulate evolution of Saccharomyces eubayanus and its lager-brewing hybrids. Mol. Ecol. 23, 2031-2045. doi: $10.1111 / \mathrm{mec} .12702$

Piper, P. W. (2011). Resistance of yeasts to weak organic acid food preservatives. Adv. Appl. Microbiol. 77, 97-113. doi: 10.1016/B978-0-12-387044-5.00004-2

Richard, P., Viljanen, K., and Penttila, M. (2015). Overexpression of PAD1 and FDC1 results in significant cinnamic acid decarboxylase activity in Saccharomyces cerevisiae. AMB Express 5:12. doi: 10.1186/s13568-015-0103-x

Salazar, A. N., Gorter de Vries, A. R., van den Broek, M., Wijsman, M., de la Torre Cortes, P., Brickwedde, A., et al. (2017). Nanopore sequencing enables near-complete de novo assembly of Saccharomyces cerevisiae reference strain CEN.K113-7D. FEMS Yeast Res. 17:fox074. doi: 10.1093/femsyr/ fox 074

Solis-Escalante, D., Kuijpers, N. G., Bongaerts, N., Bolat, I., Bosman, L., Pronk, J. T., et al. (2013). amdSYM, a new dominant recyclable marker cassette for Saccharomyces cerevisiae. FEMS Yeast Res. 13, 126-139. doi: 10.1111/15671364.12024

Steensels, J., Meersman, E., Snoek, T., Saels, V., and Verstrepen, K. J. (2014). Large-Scale selection and breeding to generate industrial yeasts with superior aroma production. Appl. Environ. Microbiol. 80, 6965-6975. doi: 10.1128/Aem. 02235-14

Twardowski, T., and Malyska, A. (2015). Uninformed and disinformed society and the GMO market. Trends Biotechnol. 33, 1-3. doi: 10.1016/j.tibtech.2014.11.006 van den Broek, M., Bolat, I., Nijkamp, J. F., Ramos, E., Luttik, M. A. H., Koopman, F., et al. (2015). Chromosomal copy number variation in Saccharomyces pastorianus is evidence for extensive genome dynamics in industrial lager brewing strains. Appl. Environ. Microbiol. 81, 6253-6267. doi: 10.1128/Aem.01263-15
Vanbeneden, N., Gils, F., Delvaux, F., and Delvaux, F. R. (2007). Variability in the release of free and bound hydroxycinnamic acids from diverse malted barley (Hordeum vulgare L.) cultivars during wort production. J. Agric. Food Chem. 55, 11002-11010. doi: 10.1021/jf072340a

Varzakas, T. H., Arvanitoyannis, I. S., and Baltas, H. (2007). The politics and science behind GMO acceptance. Crit. Rev. Food Sci. Nutr. 47, 335-361. doi: 10.1080/10408390600762696

Verduyn, C., Postma, E., Scheffers, W. A., and Vandijken, J. P. (1992). Effect of Benzoic-Acid on metabolic fluxes in yeasts - a continuous-culture study on the regulation of respiration and alcoholic fermentation. Yeast 8, 501-517. doi: 10.1002/yea.320080703

Vos, T., de la Torre Cortes, P., van Gulik, W. M., Pronk, J. T., and DaranLapujade, P. (2015). Growth-rate dependency of de novo resveratrol production in chemostat cultures of an engineered Saccharomyces cerevisiae strain. Microb. Cell Fact. 14:133. doi: 10.1186/s12934-015-0321-6

Wach, A., Brachat, A., Pohlmann, R., and Philippsen, P. (1994). New heterologous modules for classical or PCR-based gene disruptions in Saccharomyces cerevisiae. Yeast 10, 1793-1808. doi: 10.1002/yea.320101310

Walker, B. J., Abeel, T., Shea, T., Priest, M., Abouelliel, A., Sakthikumar, S., et al. (2014). Pilon: an integrated tool for comprehensive microbial variant detection and genome assembly improvement. PLoS One 9:e112963. doi: 10.1371/journal. pone. 0112963

White, M. D., Payne, K. A., Fisher, K., Marshall, S. A., Parker, D., Rattray, N. J., et al. (2015). UbiX is a flavin prenyltransferase required for bacterial ubiquinone biosynthesis. Nature 522, 502-506. doi: 10.1038/nature14559

Wickham, H. (2009). ggplot2: Elegant Graphics for Data Analysis. Berlin: SpringerVerlag. doi: 10.1007/978-0-387-98141-3

Wilson, S. M., Burton, R. A., Doblin, M. S., Stone, B. A., Newbigin, E. J., Fincher, G. B., et al. (2006). Temporal and spatial appearance of wall polysaccharides during cellularization of barley (Hordeum vulgare) endosperm. Planta 224, 655-667. doi: 10.1007/s00425-006-0244-x

Yu, J., Vasanthan, T., and Temelli, F. (2001). Analysis of phenolic acids in barley by high-performance liquid chromatography. J. Agric. Food Chem. 49, 4352-4358. doi: $10.1021 /$ jf0013407

Conflict of Interest Statement: JD, SW, JP, and J-MD have filed a patent application based on the findings of this study.

The remaining author declares that the research was conducted in the absence of any commercial or financial relationships that could be construed as a potential conflict of interest.

Copyright (c) 2018 Diderich, Weening, van den Broek, Pronk and Daran. This is an open-access article distributed under the terms of the Creative Commons Attribution License (CC BY). The use, distribution or reproduction in other forums is permitted, provided the original author(s) and the copyright owner(s) are credited and that the original publication in this journal is cited, in accordance with accepted academic practice. No use, distribution or reproduction is permitted which does not comply with these terms. 